\title{
Development and Characterization of PAR-Trackers: New Tools for Detecting Poly(ADP-ribose)
}

\author{
Short Title: \\ New Biosensors for Poly(ADP-ribose) \\ Sridevi Challa ${ }^{1,2,4}$, Keun W. Ryu ${ }^{1,2,4,5}$, Amy L. Whitaker ${ }^{1,2,3}$, \\ Jonathan C. Abshier ${ }^{1,2}$, Cristel V. Camacho ${ }^{1,2}$, and W. Lee Kraus ${ }^{1,2,6}$
}

${ }^{1}$ Laboratory of Signaling and Gene Regulation, Cecil H. and Ida Green Center for Reproductive Biology Sciences, University of Texas Southwestern Medical Center, Dallas, TX 75390, USA.

2 Division of Basic Research, Department of Obstetrics and Gynecology, University of Texas Southwestern Medical Center, Dallas, TX 75390, USA.

${ }^{3}$ Program in Genetics, Development, and Disease, Graduate School of Biomedical Sciences, University of Texas Southwestern Medical Center, Dallas, TX, 75390, USA.

4 These authors contributed equally to this work.

\section{Current Addresses:}

5 Current address: Cancer Biology \& Genetics Program, Memorial Sloan Kettering Cancer Center, New York, NY 10065.

${ }^{6}$ Address correspondence to:

W. Lee Kraus, Ph.D.

Cecil H. and Ida Green Center for Reproductive Biology Sciences

The University of Texas Southwestern Medical Center at Dallas 5323 Harry Hines Boulevard

Dallas, TX 75390-8511

Phone: 214-648-2388

Fax: 214-648-0383

E-mail: LEE.KRAUS@utsouthwestern.edu 


\section{AbSTRACT}

ADP-ribosylation (ADPRylation) is a reversible post-translation modification resulting in the covalent attachment of ADP-ribose (ADPR) moieties on substrate proteins. Naturallyoccurring protein motifs and domains, including WWEs, PBZs, and macrodomains, act as "readers" for protein-linked ADPR. Although recombinant, antibody-like ADPR detection reagents containing these readers have facilitated the detection of ADPR, they are limited in their ability to capture the dynamic nature of ADPRylation. Herein, we describe and characterize a set of poly(ADP-ribose) (PAR) Trackers (PAR-Ts) - optimized dimerization-dependent or splitprotein reassembly PAR sensors in which a naturally occurring PAR binding domain, WWE, was fused to both halves of dimerization-dependent GFP (ddGFP) or split Nano Luciferase (NanoLuc), respectively. We demonstrate that these new tools allow the detection and quantification of PAR levels in extracts, living cells, and living tissues with greater sensitivity, as well as temporal and spatial precision. Importantly, these sensors detect changes in cellular ADPR levels in response to physiological cues (e.g., hormone-dependent induction of adipogenesis without DNA damage), as well as xenograft tumor tissues in living mice. Our results indicate that PAR Trackers have broad utility for detecting ADPR in many different experimental and biological systems.

\section{KEYWORDS}

ADP-ribosylation, ADP-ribose binding domain, dimerization-dependent GFP (ddGFP), split Nano Luciferase (NanoLuc), poly(ADP-ribose) (PAR), macrodomain, PAR-binding zinc finger (PBZ), WWE domain, poly(ADP-ribose) polymerase-1 (PARP-1), PARP inhibitor. 


\section{INTRODUCTION}

ADP-ribosylation (ADPRylation) is a regulatory post-translational modification (PTM) of proteins that results in the reversible attachment of ADP-ribose (ADPR) units on substrate proteins (Gupte et al., 2017; Luscher et al., 2018). Members of the PARP family of ADPribosyltransferases (ARTs) (Ame et al., 2004; Vyas et al., 2013) function as "writers" to catalyze the transfer of ADPR moieties from oxidized $\beta$-nicotinamide adenine dinucleotide $\left(\mathrm{NAD}^{+}\right)$to a variety of amino acids (Asp, Glu, Ser, Arg, Lys) in substrate proteins (Gupte et al., 2017; Luscher et al., 2018). Mono(ADP-ribosyl) transferases (MARTs) add a single ADPR moiety to their substrates through a process called mono(ADP-ribosyl)ation (MARylation) (Challa et al., 2021), whereas poly(ADP-ribosyl) transferases (PARPs) add branched or linear chains of multiple ADPR moieties through a process called poly(ADP-ribosyl)ation (PARylation) (Gupte et al., 2017; Luscher et al., 2018). Site-specific ADPRylation of substrate proteins by PARP enzymes can have important functional consequences, including alteration of the biochemical or biophysical properties of the substrate protein or creation of new binding sites for ADPR binding domains that drive protein-protein interactions (Gibson and Kraus, 2012; Gupte et al., 2017). As such, ADPRylation can control a wide variety of cellular and biological processes, including DNA repair, DNA replication, gene expression, and RNA biology, as well as inflammatory responses and cell differentiation. (Challa et al., 2021; Gibson and Kraus, 2012; Gupte et al., 2017; Luscher et al., 2018).

The various forms of ADPR are recognized and bound by an assortment of protein domains and motifs that are found in a variety of proteins with diverse functions and mediate many of the biological functions of ADPRylation (Barkauskaite et al., 2013; Gibson and Kraus, 2012; Teloni and Altmeyer, 2016). These ADPR binding domains (ARBDs) function as "readers" of the various forms of protein-linked ADPR (MAR, PAR, branched, terminal residue, etc.). They include PARbinding motifs (PBMs), macrodomains, PAR-binding zinc fingers (PBZs), and WWE domains. (Ahel et al., 2008; Feijs et al., 2013; Gagne et al., 2008; Karras et al., 2005; Pleschke et al., 2000; Rack et al., 2016; Wang et al., 2012). Macrodomains recognize free ADPR, as well as the terminal ADPR moieties in PAR, allowing them to bind to both MAR and PAR (Karras et al., 2005; Timinszky et al., 2009). PBZ domains recognize branched forms of PAR (Chen et al., 2018). WWE domains recognize the iso-ADPR linkages joining ADPR monomers, restricting their binding to PAR (Kang et al., 2011; Wang et al., 2012; Zhang et al., 2011). In addition to the 
"writers" and "readers," "eraser" enzymes, including PAR glycohydrolase (PARG) and ADPribosylhydrolase 3 (ARH3), recognize specific ADPR modifications through the ARBDs and catalyze PAR chain degradation through endo- and exo-glycocidic activities. Their activities leave the terminal ADPR moiety attached to the acceptor amino acid residue of the substrate (Barkauskaite et al., 2013; Niere et al., 2012; Oka et al., 2006; Slade et al., 2011).

Although recent developments in mass spectrometry-based identification of ADPRmodified amino acids have enhanced the study of specific ADP-ribosylation events on target proteins (Daniels et al., 2015), the lack of a complete set of immunological tools that recognize the diverse forms of ADPR has hampered progress in studying ADPRylation. Anti-ADPR polyclonal antibodies have been reported, but the specificity and utility of these antibodies has not been assessed broadly (Bredehorst et al., 1978; Kanai et al., 1974, 1978; Meyer and Hilz, 1986; Sakura et al., 1978). Instead, the PARP field has relied on the anti-PAR monoclonal antibody 10H, which binds to PAR chains longer than ten ADPR units (Kawamitsu et al., 1984). Although useful, this antibody has left the field blind to mono- and oligo(ADP-ribosyl)ation.

The recent development of recombinant site-specific and broad-specificity antibodies to ADPR has been a major advance (Bonfiglio et al., 2020). We recently described the generation and characterization of a set of recombinant antibody-like ADP-ribose binding proteins, in which natural ARBDs have been functionalized with the Fc region of rabbit immunoglobulin (Gibson et al., 2017). Collectively, the ADPR detection tools described here are useful for cellular and biochemical assays, but they are not useful for exploring the dynamics of ADPRylation in cells and in animals. In fact, ADPRylation is a rapid process that can occur within minutes and can be removed by various 'erasers' including ARH3 and PARG (Barkauskaite et al., 2013; Gupte et al., 2017). Therefore, developing tools to measure ADPR dynamics in cells and in vivo is critical for better understating the various biological processes mediated by ADPR.

To overcome this limitation, several split-protein reassembly approaches have been applied to PAR detection. With this approach, non-functional fragments of a split-fluorescent protein or luciferase are induced to reassemble through the direct interaction of fused ADPR binding domains (Furman et al., 2011; Krastev et al., 2018; Lee et al., 2021; Serebrovskaya et al., 2020). These include the PBZ modules of aprataxin PNK-like factor (APLF) (Ahel et al., 2008) attached to each half of split firefly luciferase (split-Fluc) (Furman et al., 2011), PBZ modules with split Venus GFP (Krastev et al., 2018), and WWE domains with Turquoise and Venus, allowing for Förster 
resonance energy transfer (FRET) (Serebrovskaya et al., 2020). However, these tools have some limitations: (1) they can only detect PAR accumulation in vitro (Furman et al., 2011), (2) they can only detect PAR accumulation on specific target proteins (Krastev et al., 2018), or (3) they have modest dynamic ranges (Serebrovskaya et al., 2020). Moreover, none of these sensors can detect PAR accumulation in vivo.

In the work described herein, we developed a set of PAR Trackers (PAR-Ts) - optimized dimerization-dependent and split-protein reassembly PAR detection tools that have broad utility for both in vitro and in vivo studies. The PAR-Ts contain a WWE fused to both parts of dimerization-dependent GFP (ddGFP) (Alford et al., 2012) or split Nano Luciferase (NanoLuc) (Wang et al., 2020) with LSSmOrange. The ddGFP version (PAR-T GFP) allows for real time assessment of dynamic PAR production in vitro and in living cells, while the split NanoLuc version (PAR-T Luc) allows detection of PAR production in tissues in living mammals. 


\section{RESULTS}

The use of functionalized ARBDs to detect ADP-ribosylation has been a useful approach (Forst et al., 2013; Gibson et al., 2017; Timinszky et al., 2009). In this study, we further developed our previous ADPR detection reagents (Gibson et al., 2017) to expand their utility to in vivo applications as ADPR sensors. To achieve this, we used a systematic approach including in vitro characterization of the sensors and validation of their utility in vivo.

\section{Using dimerization-dependent GFP-based sensors to detect PAR in vitro}

Dimerization-dependent GFP is a genetically encoded sensor that was initially developed to study protein interactions (Alford et al., 2012). In this system, a pair containing a quenched GFP (ddGFPA) and a non-fluorogenic GFP (ddGFPB) form a heterodimer with improved fluorescence (Alford et al., 2012). The reversible complementation of ddGFP pairs, unlike irreversible split fluorophores, is ideal to monitor dynamic signaling events, such as PARylation (Villalobos et al., 2007). Hence, we sought to design ddGFP-based fluorescence sensors for PAR (fluorescent PAR-Trackers or PAR-T GFP) (Table 1) to enable us to perform live cell imaging, with a high signal-noise ratio. To achieve this, we fused various ADPR binding domains (ARBDs) to ddGFP-A/B and purified the recombinant proteins (Figure $1 \mathrm{~A}$ and 1B, Figure 1- figure supplement 1A). We performed in vitro ADP-ribosylation assays using recombinant PARP-1 (to generate PAR) and PARP-3 (to generate MAR) (Figure 1- figure supplement 1B and Figure 1figure supplement 1C). We observed that of all the ARBD-ddGFP pairs tested, the WWE domain from RNF146, macrodomain from AF1521, and a combination of these two performed well in specifically recognizing PARylated PARP-1 (Figure 1- figure supplement 1D and Figure 1- figure supplement 1E). These sensors recognized PARylated-PARP-1, but not MARylated PARP-3, or the precursors of ADPR (Figure 1C).

We further tested the sensitivity of these sensors and their dynamic range using in vitro PARP-1 PARylation reactions with increasing concentrations of $\mathrm{NAD}^{+}$(Figure 1- figure supplement 1F and Figure 1- figure supplement 1G) and increasing time of reaction (Figure 1D and 1E). Similarly, we detected the degradation of PAR chains by the ADP-ribosylhydrolase ARH3 in a time (Figure 1F and $1 \mathrm{G}$ ) and dose (Figure 1- figure supplement 1H) dependent manner. Further, we performed in vitro reactions by incubating the recombinant PAR-T sensors with lysates from HeLa cells treated with $\mathrm{H}_{2} \mathrm{O}_{2}$ to induce DNA damage and activate PARP-1, or an 
inhibitor of the PAR glycohydrolase PARG (i.e., PDD00017273) to increase PAR. We observed an increase in fluorescence when lysates from cells treated with either $\mathrm{H}_{2} \mathrm{O}_{2}$ or PARG inhibitor were used, as well as a profound increase in fluorescence when lysates from cells treated both $\mathrm{H}_{2} \mathrm{O}_{2}$ and PARG inhibitor were used (Figure 1- figure supplement 1I and Figure 1- figure supplement $1 \mathrm{~J}$ ). The $\mathrm{H}_{2} \mathrm{O}_{2}$ - and PARG inhibitor-stimulated signals were reduced with PARP inhibitor treatment (Figure 1- figure supplement 1I and Figure 1- figure supplement 1J). Together, these data suggest that the PAR-T GFP sensors can specifically recognize PAR, and that they exhibit a good dynamic range in vitro.

\section{Using PAR-T GFP sensors to detect PAR in live cells}

Having confirmed the specificity of the PAR-T sensors, we next sought to test their utility in live cell imaging. We expressed the PAR-T sensors in HeLa cells using doxycycline (Dox) induction and performed live cell imaging after subjecting the cells to $\mathrm{H}_{2} \mathrm{O}_{2}$-mediated PARP-1 activation (Figure 2- figure supplement 1A). The live cell PAR-T construct also expresses mCherry with a nuclear localization signal (NLS) to illuminate the nuclei and act as a control for expression of the constructs (Figure 2- figure supplement 1A). When compared to ddGFP alone, ddGFP-conjugated to WWE detected PARP-1 activation in live cell imaging (Figure 2A and 2B). Interestingly, even though the WWE-macrodomain combination sensor was able to detect PAR in vitro, this sensor combination failed to recognize PAR in cells (Figure 2- figure supplement 1B and Figure 2- figure supplement 1C). Hence, we used the WWE-based PAR-T sensors for the experiments from this point onwards. Using the WWE-based ddGFP PAR-T sensor, we were able to detect accumulation of PAR after $\mathrm{H}_{2} \mathrm{O}_{2}$-treatment in real time. Treatment with PARP inhibitor blocked this accumulation (Figure 2C and 2D).

Cancers are heterogenous tissues with spatial variation in nutrient availability and cellextrinsic stressors (Dagogo-Jack and Shaw, 2018). PAR is enhanced by stressors, such as DNA damage or hypoxia, but the spatiotemporal dynamics of PAR in cells have remained unclear due to a lack of efficient detection methods. Thus, we asked if PAR levels vary spatially in groups of cells. We performed live cell imaging in three-dimensional (3D) cancer spheroids using MCF-7 human breast cancer cells expressing the WWE-based PAR-T sensor. We observed a spatial distribution of PAR throughout the spheroid, which was inhibited by the PARP inhibitor, Olaparib (Figure 2- figure supplement 2). These data provide evidence that ddGFP based PAR-T sensors 
can be used for live cell imaging to evaluate the spatial and temporal changes in PARylation in cancer cells.

\section{Developing a highly sensitive split-luciferase PAR-T sensor}

Since we demonstrated that WWE-domain based PAR-T sensors can specifically detect PAR in biochemical assays and living cells, we sought to develop a set of highly sensitive PAR-T sensors that can detect PAR in vivo. Fluorescent sensors are not well suited for detection in vivo due to auto-fluorescence of tissues that can cause high background signals. Instead, luminescencebased approaches are preferred for in vivo applications due to lack of auto-luminescence in tissues (Tung et al., 2016). Hence, we developed a set of luminescent PAR-T sensors to detect PAR levels in vivo. We first generated sensors based on split firefly luciferase (Maita et al., 2014) using various combinations of the ARBDs. As before, the WWE domains consistently performed better in detecting an increase in PAR levels with PARG inhibitor treatment and a decrease in PAR levels with a PARP inhibitor treatment using either cell lysates (Figure 3- figure supplement 1A) or live cells (Figure 3- figure supplement 1B-S4D). Luminescence from an unsplit Firefly luciferase remained unaltered with these treatments (Figure 3- figure supplement 1D and Figure 3- figure supplement 1E).

Although split firefly luciferase-based approaches were capable of detecting signals from cells in vitro, the signal intensity from the split firefly luciferase-based PAR-T sensors were $\sim 1000$ fold less than intact firefly luciferase, which makes it difficult to use this sensor in vivo. This limitation could be due to the bulkiness of firefly luciferase that may interfere with the function of the domains fused to them in complementation assays (Wang et al., 2020; Yano et al., 2018). Therefore, we decided to employ a nano luciferase (NanoLuc)-based split luciferase complementation system (Dixon et al., 2016; Hall et al., 2012), which is a smaller, brighter, and more stable luciferase compared to firefly luciferase (Figure 3A).

To quantitatively assess the activity of this luminescent PAR-Tracker (PAR-T Luc), we expressed it in a Dox-dependent manner in human breast cancer cells that also stably express firefly luciferase (MDA-MB-231-Luc cells) (Figure 3A). In this way, we had an internal standard (i.e., the signal from the firefly luciferase), which allowed us to account for changes in cell viability or tumor size in these experiments. We first tested if there was cross reactivity of the two luciferases (NanoLuc and firefly luciferase) to the substrates; we observed specific detection of 
firefly luciferase with D-Luciferin and NanoLuc with furimazine with no cross-reactivity (Figure 3B and 3C). Moreover, the luminescence of PAR-T Luc is only 30-fold lower than intact firefly luciferase (Figure 3B). PARP-1 depletion reduced the luminescence from PAR-T Luc with little effect on the luminescence of firefly luciferase (Figure 3D-3F). Interestingly, knockdown of PARP-2 had no effect on luminescence from PAR-T Luc. Nevertheless, the luminescent PAR-T sensor is highly sensitive and can be used to detect PAR in 1,000 cells with a dynamic range of approximately three-fold (minimum to maximum) (Figure 5- figure supplement 1).

DNA damaging agents, such as UV irradiation and $\gamma$ irradiation, activate PARP-1 and promote auto and trans PARylation of PARP-1 and other DNA damage repair proteins, respectively, that are recruited to sites of DNA damage (Ray Chaudhuri and Nussenzweig, 2017). Since the PAR-T sensor can detect $\mathrm{H}_{2} \mathrm{O}_{2}$-induced PARP-1 activation (Figure 2), we assessed whether it can detect radiation-induced PARP-1 activation. We subjected the MDA-MB-231-Luc cells to Dox-induced expression of PAR-T Luc and then exposed the cells to UV radiation. We observed that UV radiation induced PARP-1 activation as assessed by an accumulation of PAR on Western blots (Figure 4A). This was further enhanced by inhibition of PARG, whereas inhibition of PARP-1 blocked the UV-induced PARP-1 activation (Figure 4A). UV radiation of PARG inhibitor-treated cells enhanced PAR-T luminescence, whereas UV radiation of PARP inhibitortreated cells reduced the PAR-T luminescence (Figure 4B and 4C). None of these treatments affected the luminescence from firefly luciferase (Figure 4B and 4D).

\section{Detection of PAR production from PARP-1 activation under physiological conditions}

We previously showed that PARP-1 catalytic activity decreases during the initial differentiation of preadipocytes (Huang et al., 2020; Luo et al., 2017; Ryu et al., 2018). Thus, adipogenesis is a unique biological process to study the dynamics of PAR accumulation from changes in PARP-1 activity under physiological conditions. We used the PAR-T Luc sensor to investigate changes in PARP-1 activity during early adipogenesis of murine preadipocytes (i.e., 3T3-L1 cells). We observed a decrease in the signal from PAR-T Luc by 12 hours of differentiation and a greater reduction in PAR-T Luc signal by 24 hours of differentiation (Figure 5), consistent with our previous observation that PARP-1 activation decreases precipitously during adipogenesis (Huang et al., 2020; Luo et al., 2017; Ryu et al., 2018). These results further highlight 
the high sensitivity of PAR-T Luc sensor, which can be used to study physiological changes in PAR levels during biological processes, such as adipogenesis.

\section{Detection of PAR production from PARP-1 activation in vivo}

To assess the in vivo utility of PAR-T Luc, we established xenograft tumors in mice using MDA-MB-231-Luc cells and induced the expression of PAR-T Luc with Dox (Figure 6A). Similar to the in vitro experiments, we could detect an increase in PAR levels with the PAR-T Luc sensor when the mice were treated with both $\gamma$ irradiation and PARG inhibitors, but the signal was decreased when the mice were treated with PARP inhibitor (Figure 6B). We normalized the signal from PAR-T to luminescence from firefly luciferase to confidently measure the differences in PAR levels, while accounting for the variability in tumor sizes (Figure 6C). These results demonstrate that the PAR-T Luc sensor has sufficient sensitivity to detect dynamic changes in PAR production in in tissues of living animals in vivo. 


\section{DISCUSSION}

Naturally occurring ADPR binding domains (ARBDs) have been invaluable tools for developing novel ADPR detection reagents and sensors (Forst et al., 2013; Gibson et al., 2017; Timinszky et al., 2009). In this study, we developed a set of PAR sensors that are useful tools for in vitro assays, live cells, and tissues in living animals (Table 1). To this end, we constructed a ddGFP-based fluorescent PAR-Tracker (PAR-T) that can be used for in vitro assays and live cell imaging, to track PAR levels in a single cell (Figure 2). In addition, we made a split NanoLucbased luminescent PAR-T containing LSSmOrange that is extremely sensitive and can be used to detect PAR in xenograft tumors in living mice (Figure 6).

\section{Previously developed PAR sensors}

In previous work, Furman et al. (2010) made a bivalent split-protein PAR-specific sensor encompassing the PAR-binding zinc finger (PBZ) modules of aprataxin PNK-like factor (APLF) (residues 376-441) (Ahel et al., 2008) attached to each half of split firefly luciferase (split-Fluc) (Furman et al., 2011). This tool allows detection of PAR from biochemical reactions and cell lysates (Furman et al., 2011). Krastev et al. (2018) also made an APLF PBZ domain-fused split fluorescence sensor based on Venus fluorescent protein to detect PAR (Krastev et al., 2018). In a recent study, Serebrovskaya et al. (2020) developed FRET-based PAR sensors by fusing the WWE domain from RNF146 to the Torquoise2 and Venus fluorescent proteins (Serebrovskaya et al., 2020). These sensors detect PAR formation in live cells (Krastev et al., 2018; Serebrovskaya et al., 2020).

However, the aforementioned approaches for PAR sensors have the following limitations. (1) they are irreversible, thus limiting their use for measuring dynamic changes in PAR levels, (2) the requirement for measuring filtered light emissions in FRET-based sensors results in low signal intensities and narrow dynamic ranges that limit their utility in a variety of applications, (3) PBZ domains detect branched PAR chains synthesized predominantly by PARP-2 (Chen et al., 2018), and (4) they are unable to measure PAR levels in vivo. To overcome these limitations, we developed a set of PAR sensors in which ARBDs are fused to ddGFP or split luciferase. Assembly of dimerization-dependent fluorophores and split luciferase proteins are reversible and have a higher signal intensity (Alford et al., 2012; Luker et al., 2004). In our screen for the best ARBDs for PAR detection, the WWE domain from RNF146 and the macrodomain from AF1521 exhibited 
superior detection of PAR production by activated PARP-1, compared to the PBZ domains from APLF or the macro H2A.1 macrodomain (Figure 1- figure supplement 1E and Table 1). Thus, although useful, the currently available PAR sensors have multiple opportunities for improvement.

\section{Detection of PAR in tissues in living animals}

A major goal of this work was to generate a sensor with sufficient stability and sensitivity to allow detection of PAR in tissues in living animals. We faced several challenges in doing so. For example, fluorescent sensors are not optimal for use in vivo due to high auto-fluorescence of tissues, thus we had to use a luminescent sensor to increase the sensitivity of PAR detection in vivo. Although intact luciferase can be used in cells as reporter, achieving usable signals from split luciferase is technically challenging because (1) it is difficult to express, (2) the luminescence of split luciferase is typically 100-1000 fold less than intact luciferase, and (3) the wavelength emitted by luciferase exhibits poor penetration in tissues. A broadly useful PAR detection tool would need to overcome these limitations and allow real-time dynamic observations in cells and detection in tissues.

To this end, we optimized several aspects of the sensor to achieve the highest sensitivity: (1) we used NanoLuc, the smallest and brightest luciferase available (Wang et al., 2020), (2) we added LSSmOrange to stabilize the C-terminal fragment of NanoLuc (Schaub et al., 2015), (3) we used the Nano-Glo live cell substrate to be able to perform these assays in live cells, (4) we used Dox-inducible constructs to avoid any effects of expression of these constructs on cell viability, and (5) we developed a dual luciferase assay to quantify PAR levels more accurately. The blueshifted emission of NanoLuc (at $460 \mathrm{~nm}$ ) diffuses rapidly in tissues and hence it is not optimal for imaging deep tissues (Schaub et al., 2015). Therefore, we fused the C-terminal domain of NanoLuc with LSSmOrange fluorescent protein (red-shifted GFP variant), which has a higher fluorescence quantum yield that is compatible for excitation by the light emitted by NanoLuc. Upon addition of the luciferase substrate, the bioluminescence energy from NanoLuc excites the LSSmOrange fluorophore, shifting the emission energy to $570 \mathrm{~nm}$ via BRET reaction (Schaub et al., 2015).

In summary, we generated a set of PAR-Trackers with significant improvements in functionality over our previous detection reagents. The PAR-T Luc sensor can detect PAR levels 
in as few as 1000 cells with a good dynamic range of detection (Figure 5 - figure supplement 1) and it can also detect PAR in tissues in living animals (Figure 6).

\section{Perspective and Future Advances for PAR Sensors}

Current studies on PARylation are limited to in vitro biochemical assays and end-point cellular assays. Moreover, the techniques routinely used to measure PAR levels require laborious and time consuming assays, such as Western blotting, ELISA, immunofluorescence, or immunohistochemistry. The high sensitivity and low signal to noise ratios of the PAR-Trackers described here enable spatial and temporal monitoring of PAR levels in cells and in animals. Moreover, these techniques do not require exogenous ligands and involve limited manipulation to cells that can limit artifacts caused by sample handling, such as lysing or fixing of cells. Generating animal models with tissue-specific expression of the PAR-T Luc sensor will enable monitoring PAR levels in specific cell types in vivo. 


\section{FigURE SUPPLEMENTS}

Figure 1- figure supplement 1. Characterization of fluorescence-based PAR-Trackers using biochemical assays.

Figure 2 - figure supplement 1 . Characterization of fluorescence-based PAR-Trackers using live cell imaging.

Figure 2 - figure supplement 2. Spatially tracking PAR formation using PAR-T GFP.

Figure 3 - figure supplement 1. Characterization of a luminescence-based PAR-Tracker.

Figure 5 - figure supplement 1. Measuring the levels of PAR in a limited number of cells using PAR-T Nano luciferase.

\section{ACKNOWLEDGEMENTS}

We thank Dr. Rebecca Gupte for technical assistance in purifying the recombinant proteins and for critical comments on this manuscript. We acknowledge and thank the following UT Southwestern core facilities: Live Cell Imaging Core for microscopy support (Dr. Katherine LubyPhelps) and Flow Cytometry Core for performing FACS (Dr. David Farrar). The authors would like to acknowledge the assistance of the Southwestern Small Animal Imaging Shared Resource, which is supported in part by the Harold C. Simmons Cancer Center through an NCI Cancer Center Support Grant, P30 CA142543.

\section{FINANCIAL SUPPORT}

This work was supported by a grant from the NIH/National Institute of Diabetes and Digestive and Kidney Diseases (NIDDK) (R01 DK058110), a grant from the Cancer Prevention and Research Institute of Texas (RP190236), and funds from the Cecil H. and Ida Green Center for Reproductive Biology Sciences Endowment to W.L.K.

\section{DisCLOSURES}

W.L.K. is a founder and consultant for Ribon Therapeutics, Inc. and ARase Therapeutics, Inc. He is also coholder of U.S. Patent 9,599,606 covering the ADP-ribose detection reagent used herein, which has been licensed to and is sold by EMD Millipore.

\section{Patent}

K.W.R., S.C., and W.L.K. have a patent pending for the PAR-T sensors described herein. 


\section{Data Availability}

All unprocessed Western blot image data and data from individual replicates from the fluorescent and luminescent assays can be found here:

DOI: $10.17632 / x 9 j 73 t d b 5 r .1$

Mendeley Data

https://data.mendeley.com/datasets/x9j73tdb5r/draft?a=9020b6ab-2e37-44d8-815e-

$\underline{\text { bc03a9cdabb3 }}$

[Note: this link is currently only active for reviewers of the manuscript]

The work does not contain any high complexity, high content "omics" data. 


\section{MAterials AND Methods}

\section{Key resources table}

\begin{tabular}{|c|c|c|c|c|}
\hline $\begin{array}{l}\text { Reagent type } \\
\text { (species) or } \\
\text { resource }\end{array}$ & Designation & $\begin{array}{l}\text { Source or } \\
\text { reference }\end{array}$ & Identifiers & $\begin{array}{l}\text { Additional } \\
\text { information }\end{array}$ \\
\hline $\begin{array}{l}\text { strain, strain } \\
\text { background } \\
\text { (Escherichia } \\
\text { coli) }\end{array}$ & $\begin{array}{l}\text { BL21(DE3- } \\
\text { pLysis) }\end{array}$ & ThermoFisher & Cat. No. C606010 & \\
\hline $\begin{array}{l}\text { cell line (Homo } \\
\text { sapiens) }\end{array}$ & $\begin{array}{l}\text { MCF7 (female } \\
\text { adult breast } \\
\text { cancer) }\end{array}$ & ATCC & RRID:CVCL_0031 & \\
\hline $\begin{array}{l}\text { cell line (Homo } \\
\text { sapiens) }\end{array}$ & $\begin{array}{l}3 \text { T3-L1 (male } \\
\text { adult pre- } \\
\text { adipocyte) }\end{array}$ & ATCC & RRID:CVCL_0123 & \\
\hline $\begin{array}{l}\text { cell line (Homo } \\
\text { sapiens) }\end{array}$ & $\begin{array}{l}\text { HeLa (female } \\
\text { adult cervical } \\
\text { cancer) }\end{array}$ & ATCC & RRID:CVCL_0030 & \\
\hline $\begin{array}{l}\text { cell line (Homo } \\
\text { sapiens) }\end{array}$ & $\begin{array}{l}\text { MDA-MB-231 } \\
\text { Luc (Female } \\
\text { adult breast } \\
\text { cancer) }\end{array}$ & $\begin{array}{l}\text { Obtained from } \\
\text { Dr. Srinivas } \\
\text { Malladi, UT } \\
\text { Southwestern }\end{array}$ & & \\
\hline $\begin{array}{l}\text { cell line (Homo } \\
\text { sapiens) }\end{array}$ & $\begin{array}{l}\text { HEK 293T } \\
\text { (normal } \\
\text { embryonic } \\
\text { kidney) }\end{array}$ & ATCC & RRID:CVCL_0063 & \\
\hline $\begin{array}{l}\text { transfected } \\
\text { construct } \\
\text { (Homo sapiens) }\end{array}$ & $P A R P I$ siRNA & $\begin{array}{l}\text { Sigma- } \\
\text { Aldrich }\end{array}$ & $\begin{array}{l}\text { Cat. No. } \\
\text { SASI_Hs01_003327 } \\
7\end{array}$ & \\
\hline $\begin{array}{l}\text { transfected } \\
\text { construct } \\
\text { (Homo sapiens) }\end{array}$ & $P A R P 2$ siRNA & $\begin{array}{l}\text { Sigma- } \\
\text { Aldrich }\end{array}$ & $\begin{array}{l}\text { Cat. No. } \\
\text { SASI_Hs01_0013- } \\
1488\end{array}$ & \\
\hline antibody & $\begin{array}{l}\text { Anti-poly- } \\
\text { ADP-ribose } \\
\text { binding reagent } \\
\text { (rabbit } \\
\text { monoclonal; } \\
\text { IgG Fc) }\end{array}$ & Millipore & $\begin{array}{l}\text { Cat. No. } \\
\text { MABE1013 }\end{array}$ & $\begin{array}{l}\text { Gibson et al., } 2017 \\
\text { WB }(5 \mu \mathrm{g} / \mathrm{mL})\end{array}$ \\
\hline
\end{tabular}




\begin{tabular}{|c|c|c|c|c|}
\hline antibody & $\begin{array}{l}\text { PARP-1 (rabbit } \\
\text { polyclonal) }\end{array}$ & Active Motif & Cat. No. 39559 & WB $(1: 1000)$ \\
\hline antibody & $\begin{array}{l}\beta \text {-tubulin } \\
\text { (rabbit } \\
\text { polyclonal) }\end{array}$ & Abcam & $\begin{array}{l}\text { Cat. No. ab6046 } \\
\text { RRID: AB_2210370 }\end{array}$ & WB $(1: 1000)$ \\
\hline antibody & $\begin{array}{l}\text { HRP- } \\
\text { conjugated } \\
\text { anti-rabbit IgG } \\
\text { (goat } \\
\text { polyclonal) }\end{array}$ & Pierce & $\begin{array}{l}\text { Cat. No. } 31460 \\
\text { RRID: AB_228341 }\end{array}$ & WB $(1: 5000)$ \\
\hline $\begin{array}{l}\text { commercial } \\
\text { assay or kit }\end{array}$ & $\begin{array}{l}\text { Nano-Glo Live } \\
\text { Cell Assay } \\
\text { System }\end{array}$ & Promega & Cat. No. N2011 & \\
\hline $\begin{array}{l}\text { commercial } \\
\text { assay or kit }\end{array}$ & $\begin{array}{l}\text { Nano-Glo } \\
\text { Luciferase } \\
\text { Assay System }\end{array}$ & Promega & Cat. No. N1110 & \\
\hline $\begin{array}{l}\text { commercial } \\
\text { assay or kit }\end{array}$ & $\begin{array}{l}\text { Luciferase } \\
\text { Assay System }\end{array}$ & Promega & Cat. No. E1500 & \\
\hline
\end{tabular}

\section{Cell culture and treatments}

HeLa, 293T, 3T3-L1, and MCF-7 cells were obtained from the American Type Cell Culture, and MDA-MB-231-luc cells were obtained from Dr. Srinivas Malladi, UT Southwestern Medical Center. Fresh cell stocks were regularly replenished from the original stocks, verified for cell type identity using the GenePrint 24 system (Promega, B1870), and confirmed as mycoplasma-free using a commercial testing kit every three months.

HeLa, 293T, and MCF-7 cells were cultured in DMEM (Sigma-Aldrich, D5796) supplemented with 10\% fetal bovine serum (Sigma, F8067) and 1\% penicillin/streptomycin. 3T3L1 cells were cultured in DMEM (Cellgro, 10-017-CM) supplemented with $10 \%$ fetal bovine serum (Atlanta Biologicals, S11550) and 1\% penicillin/streptomycin. For the luciferase assays, 5,000 3T3-L1 cells were plated in each well of a 96-well format plate. For the induction of adipogenesis, the 3T3-L1 cells were grown to confluence and then cultured for two more days until contact inhibited. The cells were then treated for two days with MDI adipogenic cocktail containing $0.25 \mathrm{mM}$ IBMX, $1 \mu \mathrm{M}$ dexamethasone, and $10 \mu \mathrm{g} / \mathrm{mL}$ insulin for 12 hours or 24 hours as indicated. Expression of PAR-T Luc was induced by treating the 3T3-L1 cells with doxycycline (Dox) for 24 hours before the luciferase assay was performed.

In some cases, the cells were treated with various inhibitors as described herein. For inhibition of nuclear PARPs, the cells were treated with PJ-34 (20 $\mu \mathrm{M}$; Enzo, ALX-270) or Olaparib (20 $\mu \mathrm{M}$; MedChem Express, HY-10162) for 2 hours. For inhibition of PARG, the cells were treated with PDD00017273 (20 $\mu$ M; MedChem Express, HY-108360) for 2 hours. For UVinduced DNA damage, the cells were treated with $50 \mathrm{~mJ} / \mathrm{cm}^{2} \mathrm{UV}$ irradiation for 15 minutes. 
Vectors for ectopic expression and knockdown

The vectors described below were generated using the oligonucleotide primers described in the next section. All constructs were verified by sequencing.

Mammalian expression vectors. The plasmids for Dox-inducible expression of the ddGFP PAR-T constructs were generated using a cDNA for ddGFP-A (Addgene, 40286) or ddGFP-B (Addgene, 40287). cDNAs for the PAR binding domains were amplified from previously published pET19b constructs (Gibson et al., 2017). The cDNAs were assembled and cloned first into pCDNA3 and then into pInducer20 or pET19b using Gibson assembly (NEB, E2621). The split luciferase constructs were synthesized as gene blocks (Integrated DNA Technologies), and then cloned into the pInducer20 vectors using Gibson assembly.

\section{List of oligonucleotide primers used for cloning}

Primers for cloning ddGFPA-ddGFPB into pCDNA3

Forward 1: 5' - AGGGGCGGAATTCCTCTAGTTCAATGCCCCAGGTGGTG -3'

Reverse 1: 5' - AGGGGCGGAATTCCTCTAGTTCAATGCCCCAGGTGGTG -3'

Forward 2: 5' - ATTACGCTCTTGAAGCAACCATGGCCACCATCAAAGAGTTCATGC -3'

Reverse 2: 5' - TAGGGCCCTCTAGATGCATGTTACTTGTACCGCTCGTC -3'

\section{Primers for cloning WWE-ddGFPA and WWE-ddGFPB into pCDNA3}

Forward 1: 5'-

ATGACAAGCTTGAAGCAACCGGAAATGGTGAATATGCATGGTATTATG -3'

Reverse 1: 5'- AGGGGCGGAATTCCTCTAGTTCAATGCCCCAGGTGGTG -3'

Forward 2: 5' - ATTACGCTCTTGAAGCAACCGGAAATGGTGAATATGCATG -3'

Reverse 2: 5' - TAGGGCCCTCTAGATGCATGTTACTTGTACCGCTCGTC -3'

\section{Primers for cloning ddGFPA or ddGFPB into pET19b}

pET19b-ddGFPA Forward:

5'-TATCGACGACGACGACAAGCATATGCTCGAGATGGCGAGCAAGAGCGAG -3'

pET19b-ddGFPA Reverse:

5’- TCGGGCTTTGTTAGCAGCCGGATCCTCAATGCCCCAGGTGGTG -3’

pET19b-ddGFPB Forward:

5' - TATCGACGACGACGACAAGCATATGCTCGAGACCATCAAAGAGTTCATGC -3'

pET19b-ddGFPB Reverse:

5' - TCGGGCTTTGTTAGCAGCCGGATCCTTACTTGTACCGCTCGTC -3’

Primers for cloning WWE-ddGFPA or WWE-ddGFPB into pET19b

pET19b-WWE-ddGFPA Forward:

5' - TATCGACGACGACGACAAGCATATGCTCGAGGGAAATGGTGAATATGCATG -3'

pET19b-WWE- ddGFPA Reverse:

5' - TCGGGCTTTGTTAGCAGCCGGATCCTCAATGCCCCAGGTGGTG -3’

pET19b-WWE-ddGFPB Forward:

5' - TATCGACGACGACGACAAGCATATGCTCGAGGGAAATGGTGAATATGCATG -3' pET19b-WWE- ddGFPB Reverse: 
5'- TCGGGCTTTGTTAGCAGCCGGATCCTTACTTGTACCGCTCGTC -3’

Primers for cloning MacroH2A.1-ddGFPA or MacroH2A.1-ddGFPB into pET19b

Forward 1:

5'-TATCGACGACGACGACAAGCATATGCTCGAGGGTGAAGTCAGTAAGGCAGC -3'

Reverse 1:

5'-AGAATTCTAGGTTGGCGTCCAGCTTGGC -3'

pET19b-MacroH2A.1-ddGFPA Forward:

5' - GGACGCCAACCTAGAATTCTCGACAGGGCATG-3'

pET19b-MacroH2A.1-ddGFPA Reverse:

5’ - TCGGGCTTTGTTAGCAGCCGGATCCTCAATGCCCCAGGTGGTG -3'

pET19b-MacroH2A.1-ddGFPB Forward:

5'- GGACGCCAACCTAGAATTCTCGACAGGG -3'

pET19b-MacroH2A.1-ddGFPB Reverse:

5' - TCGGGCTTTGTTAGCAGCCGGATCCTTACTTGTACCGCTCGTC -3’

Primers for cloning PBZ-ddGFPA or PBZ-ddGFPB into pET19b

Forward 1:

5' - TATCGACGACGACGACAAGCATATGCTCGAGGATTCAGTTCTACAAGGTTC -3'

Reverse 1: 5' - AGAATTCTAGTGGAAGCGTATTATGTCTATATTC -3'

pET19b-PBZ-ddGFPA Forward:

5' - TACGCTTCCACTAGAATTCTCGACAGGGCATG -3'

pET19b-PBZ-ddGFPA Reverse:

5'- TCGGGCTTTGTTAGCAGCCGGATCCTCAATGCCCCAGGTGGTG -3'

pET19b-PBZ-ddGFPB Forward:

5' - TACGCTTCCACTAGAATTCTCGACAGGG -3'

pET19b-PBZ-ddGFPB Reverse:

5' - TCGGGCTTTGTTAGCAGCCGGATCCTTACTTGTACCGCTCGTC -3’’

\section{Primers for cloning MacroAF-ddGFPA or PBZ-ddGFPB into pET19b}

Forward 1:

5' - TATCGACGACGACGACAAGCATATGCTCGAGATGGAACGGCGTACTTTAATC -3'

Reverse 1: 5' - AGAATTCTAGAAGACTCCTCTCAAAGAC -3'

pET19b-MacroAF -ddGFPA Forward:

5'- GAGGAGTCTTCTAGAATTCTCGACAGGGCATG -3'

pET19b-PBZ-ddGFPA Reverse:

5'- TCGGGCTTTGTTAGCAGCCGGATCCTCAATGCCCCAGGTGGTG -3'

pET19b-MacroAF -ddGFPB Forward:

5'- GAGGAGTCTTCTAGAATTCTCGACAGGG -3' 
pET19b-PBZ-ddGFPB Reverse:

5’ - TCGGGCTTTGTTAGCAGCCGGATCCTTACTTGTACCGCTCGTC -3’’

Primers for cloning WWE-ddGFP (PAR-T GFP) sensors and control ddGFP into pInducer20 Forward: 5'- TCCGCGGCCCCGAACTAGTGGCCACCATGGACTACAAG -3'

Reverse: 5'- AGAGGGGCGGAATTCCTCTAGTCTTACTTGTACCGCTCGTC -3'

\section{Primers for cloning AF-ddGFP sensors into pInducer 20}

Forward 1:

5'-

TCCGCGGCCCCGAACTAGTGGCCACCATGGACTACAAGGATGACGATGACAAGCTT GAAGCAACCATGGAACGGCGTACTTTAATCATG -3'

Reverse 1: 5' - TTCCTCTAGTTCAATGCCCCAGGTGGTG -3'

Forward 2: 5' - GGGGCATTGAACTAGAGGAATTCCGCCC -3'

Reverse 2: 5' - AGAGGGGCGGAATTCCTCTAGTCTTACTTGTACCGCTCGTC -3'

\section{Primers for cloning split firefly luciferase (PAR-T fLuc) sensors into pCDNA3}

pCDNA3- WWE/MacroAF-LucN:

Forward 1: 5'- CAAGCTTGGTACCGAGCTCGGCCACCATGGACTACAAG-3'

Reverse 1: 5' - CCATGGATCCTGAACTACCGGTCGATTC -3'

Forward 2: 5' - CGGTAGTTCAGGATCCATGGAAGACGCC -3'

Reverse-2: 5' - AGGGCCCTCTAGATGCATGCTCACATAATCATAGGTCCTCTGAC -3'

pCDNA3- WWE/MacroAF-LucC:

Forward 1: 5'- CAAGCTTGGTACCGAGCTCGGCCACCATGGACTACAAG-3'

Reverse 1: 5' - GTCCGGATCCTGAACTACCGGTCGATTC -3'

Forward 2: 5' - CGGTAGTTCAGGATCCGGACCTATGATTATG -3'

Reverse-2: 5' - AGGGCCCTCTAGATGCATGCTTACAATTTGGACTTTCCG -3'

Primers for cloning split Nano luciferase sensors (PAR-T Luc) into pInducer20

Forward 1: 5' - TCCGCGGCCCCGAACTAGTGATGGACTACAAGGATGAC -3'

Reverse 1: 5' - CTCCGCTTCCACTGTTGATGGTTACTCG -3'

Forward 2: 5' - CATCAACAGTGGAAGCGGAGCCACGAAC -3'

Reverse-2: 5'- GTTTAATTAATCATTACTACTTACTTGTACAGCTCGTCCATGC -3'

\section{Knockdown of $P A R P 1$ and $P A R P 2$ using siRNAs}

Commercially available siRNA oligos targeting PARP1 (Sigma, SASI_Hs01_0033277), PARP2 (Sigma, SASI_Hs01_0013-1488) and control siRNA (Sigma, SIC001) were transfected at a final concentration of $30 \mathrm{nM}$ using Lipofectamine RNAiMAX reagent (Invitrogen, 13778150) according to the manufacturer's instructions. All experiments were performed 48 hours after siRNA transfection.

\section{Generation of stable cell lines}

Cells were transfected with lentiviruses for stable ectopic expression. We generated lentiviruses by transfection of the pInducer20 constructs described above, together with an 
expression vector for the VSV-G envelope protein (pCMV-VSV-G, Addgene plasmid no. 8454), an expression vector for GAG-Pol-Rev (psPAX2, Addgene plasmid no. 12260), and a vector to aid with translation initiation (pAdVAntage, Promega) into 293T cells using GeneJuice transfection reagent (Novagen, 70967) according to the manufacturer's protocol. The resulting viruses were used to infect HeLa, MCF-7, 3T3-L1 or MDA-MB-231 cells in the presence of 7.5 $\mu \mathrm{g} / \mathrm{mL}$ polybrene 24 hours and 48 hours, respectively, after initial $293 \mathrm{~T}$ transfection. Stably transduced cells were selected with $500 \mu \mathrm{g} / \mathrm{mL} \mathrm{G418} \mathrm{sulfate} \mathrm{(Sigma,} \mathrm{A1720).} \mathrm{For} \mathrm{inducible}$ expression of RPL24, the cells were treated with $1 \mu \mathrm{g} / \mathrm{mL}$ doxycycline (Dox) for 24 hours.

\section{Preparation of cell lysates}

Cells were cultured and treated as described above for the preparation of cell extracts. At the conclusion of the treatments, the cells were washed twice with ice-cold PBS and lysed with Lysis Buffer (20 mM Tris- $\mathrm{HCl}$ pH 7.5, 150 mM NaCl, 1 mM EDTA, 1 mM EGTA, 1\% NP-40, $1 \%$ sodium deoxycholate, $0.1 \%$ SDS) containing $1 \mathrm{mM} \mathrm{DTT,} 250 \mathrm{nM}$ ADP-HPD (Sigma, A0627), $10 \mu \mathrm{M}$ PJ34 (Enzo, ALX-270), and 1x complete protease inhibitor cocktail (Roche, 11697498001). The cells were incubated in the Lysis Buffer for 30 minutes on ice with gentle vortexing and then centrifuged at full speed for 15 minutes at $4^{\circ} \mathrm{C}$ in a microcentrifuge to remove the cell debris.

\section{Western blotting}

Protein concentrations of the cell lysates were determined using a Bio-Rad Protein Assay Dye Reagent (Bio-Rad, 5000006). Volumes of lysates containing equal amounts of total protein were boiled at $100^{\circ} \mathrm{C}$ for 5 minutes after addition of $1 / 4$ volume of $4 x$ SDS-PAGE Loading Solution (250 mM Tris, pH 6.8, 40\% glycerol, 0.04\% Bromophenol Blue, 4\% SDS), run on 6\% polyacrylamide-SDS gels, and transferred to nitrocellulose membranes. After blocking with 5\% nonfat milk in TBST, the membranes were incubated with the primary antibodies described above in $1 \%$ non-fat milk in TBST with $0.02 \%$ sodium azide, followed by anti-rabbit HRP-conjugated IgG (1:5000) or anti-mouse HRP-conjugated IgG (1:5000). Immunoblot signals were detected using an ECL detection reagent (Thermo Fisher Scientific, 34577, 34095).

\section{Antibodies}

The custom rabbit polyclonal antiserum against PARP-1 was generated in-house by using purified recombinant amino-terminal half of PARP-1 as an antigen (now available Active Motif; cat. no. 39559). The custom recombinant antibody-like anti-poly-ADP-ribose binding reagent (anti-PAR) was generated and purified in-house (now available from EMD Millipore, MABE1031). The other antibodies used were as follows: PARP-2 (Santa Cruz, sc-150X), $\beta$ Tubulin (Abcam, ab6046), goat anti-rabbit HRP-conjugated IgG (Pierce, 31460).

\section{Purification of PAR-T sensor proteins expressed in bacteria}

His-tagged PAR detection reagents in the pET19b-based bacterial expression vector were expressed in E. coli strain BL21(DE3-pLysis). The transformed bacteria were grown in LB containing ampicillin at $37^{\circ} \mathrm{C}$ until the $\mathrm{OD}_{595}$ reached 0.4-0.6. Recombinant protein expression was induced by the addition of $1 \mathrm{mM}$ IPTG for 3 hours at $37^{\circ} \mathrm{C}$. The cells were collected by centrifugation, and the cell pellets were flash-frozen in liquid nitrogen and stored at $-80{ }^{\circ} \mathrm{C}$ until further use. The frozen cell pellets were thawed on ice and lysed by sonication in Ni-NTA Lysis Buffer (10 mM Tris-HCl pH 7.5, 0.15 M NaCl, 0.5 mM EDTA, 0.1\% NP-40, 10\% glycerol, $1 \mathrm{mM}$ $\mathrm{PMSF}$, and $1 \mathrm{mM} \beta$-mercaptoethanol). The lysates were clarified by centrifugation at 15,000 rpm 
using an SS34 rotor (Sorvall) at $4^{\circ} \mathrm{C}$ for 30 minutes. The supernatant was incubated with $1 \mathrm{~mL}$ of Ni-NTA resin equilibrated in Ni-NTA Lysis Buffer at $4{ }^{\circ} \mathrm{C}$ for 2 hours with gentle mixing. The resin was collected by centrifugation at $4{ }^{\circ} \mathrm{C}$ for 10 minutes at $1,000 \mathrm{x} \mathrm{g}$, and the supernatant was removed. The resin was washed five times with Ni-NTA Wash Buffer (10 mM Tris-HCl pH 7.5, $0.3 \mathrm{M} \mathrm{NaCl}, 0.2 \% \mathrm{NP}-40,10 \%$ glycerol, $15 \mathrm{mM}$ imidazole, $1 \mathrm{mM}$ PMSF and $1 \mathrm{mM} \beta-$ mercaptoethanol). The recombinant proteins were then eluted using Ni-NTA Elution Buffer (10 $\mathrm{mM}$ Tris- $\mathrm{HCl} \mathrm{pH}$ 7.5, $0.2 \mathrm{M} \mathrm{NaCl}, 0.1 \% \mathrm{NP}-40,10 \%$ glycerol, $500 \mathrm{mM}$ imidazole, $1 \mathrm{mM}$ PMSF, and $1 \mathrm{mM} \beta$-mercaptoethanol). The eluates were collected by centrifugation at $4{ }^{\circ} \mathrm{C}$ for 10 minutes at $1,000 \mathrm{xg}$, and dialyzed in Ni-NTA Dialysis Buffer $(10 \mathrm{mM}$ Tris- $\mathrm{HCl} \mathrm{pH} 7.5,0.15 \mathrm{M} \mathrm{NaCl}$, $10 \%$ glycerol, $1 \mathrm{mM}$ PMSF, and $1 \mathrm{mM} \beta$-mercaptoethanol). The dialyzed proteins were quantified using a Bradford protein assay (Bio-Rad), aliquoted, flash-frozen in liquid N2, and stored at $-80^{\circ} \mathrm{C}$.

\section{Detection of PAR by PAR-T sensors in vitro}

The following methods were used to measure PAR levels using the recombinant PAR-T constructs in vitro.

In vitro auto ADP-ribosylation assays. In vitro auto ADP-ribosylation assays were performed essentially as described previously (Gibson et al., 2017). The ADP-ribosylation reactions contained $0.2 \mu \mathrm{M}$ purified PARP-1 or PARP-3 and $100 \mathrm{ng} / \mu \mathrm{L}$ of sheared salmon sperm DNA (Invitrogen, AM9680). Purified proteins were mixed with the indicated amounts of NAD ${ }^{+}$ in ADP-ribosylation Buffer $\left(50 \mathrm{mM}\right.$ Tris- $\left.\mathrm{HCl} \mathrm{pH} 7.5,0.125 \mathrm{M} \mathrm{NaCl}, 12.5 \mathrm{mM} \mathrm{MgCl}_{2}\right)$. The reactions were incubated at room temperature for 15 minutes and terminated by addition of 200 nM PJ34.

Tracking PAR formation in vitro. For characterizing the specificity of PAR tracking proteins, recombinant PAR-T sensor proteins $(200 \mathrm{nM})$ were incubated with either of the following: $500 \mu \mathrm{M} \mathrm{NAD}^{+}, 500 \mu \mathrm{M}$ NAM, $50 \mu \mathrm{M}$ free ADP-ribose, $500 \mu \mathrm{M}$ NMN, $5 \mathrm{mM}$ ATP and $100 \mu \mathrm{M}$ NADH ATP, or with $5 \mathrm{nM}$ PARP-1 or PARP-3 proteins in the ADP-ribosylation Buffer (50 mM Tris- $\mathrm{HCl} \mathrm{pH} 7.5,0.125 \mathrm{M} \mathrm{NaCl}, 12.5 \mathrm{mM} \mathrm{MgCl}_{2}$ ) for 15 minutes at room temperature followed by spectroscopy.

For time course experiments, in vitro ADP-Ribosylation assays were performed as described above in the presence of $200 \mathrm{nM}$ of recombinant PAR-T sensor proteins. Two hundred and fifty $\mu \mathrm{M} \mathrm{NAD}{ }^{+}$was added and the reaction was allowed to proceed for 16 minutes. The fluorescence intensities were measured every 30 seconds using a plate reader (CLARIOstar BMG Labtech). A similar in vitro ADP-ribosylation reaction was performed and processed for western blotting as described above.

Tracking PAR degradation in vitro. For measuring the level of $\mathrm{PAR}$ degradation in vitro, $5 \mathrm{nM}$ of PARP-1 and $200 \mathrm{nM}$ recombinant PAR-T sensor proteins were incubated in ADPribosylation Buffer along with the indicated amounts of ARH3. The reaction mixture was incubated at $37^{\circ} \mathrm{C}$ for the indicated amount of time and fluorescence intensities were measured.

Tracking PAR formation in cell extracts. For measuring the levels of PAR in mammalian cell lysates, HeLa cells subjected to Dox-induced expression of the PAR-T sensor proteins were treated with $20 \mu \mathrm{M}$ PJ34 or $20 \mu \mathrm{M}$ PDD 00017273 for 2 hours prior to induction of DNA damage by treatment with $\mathrm{H}_{2} \mathrm{O}_{2}(1 \mathrm{mM}$; Sigma, 216763) for 10 minutes. The cells were then lysed in Lysis Buffer $(20 \mathrm{mM}$ Tris-HCl pH 7.5, $150 \mathrm{mM} \mathrm{NaCl,} 1 \mathrm{mM}$ EDTA, $1 \mathrm{mM}$ EGTA, 1\% NP-40, 1\% sodium deoxycholate, 0.1\% SDS) containing 1 mM DTT, $250 \mathrm{nM}$ ADP-HPD (Sigma, A0627), 10 $\mu \mathrm{M}$ PJ34 (Enzo, ALX-270), and 1x complete protease inhibitor cocktail (Roche, 11697498001). 
Equal volumes of the lysate and ADP-ribosylation Buffer were incubated with $200 \mathrm{nM}$ of recombinant PAR sensor proteins. The reaction mixture was incubated at room temperature for 15 minutes and the fluorescence intensity was measured.

Measurement of in vitro fluorescence changes using spectroscopy. Purified sensor and control proteins $(200 \mathrm{nM})$ were incubated with the purified proteins or cell extracts in a volume of $100 \mu \mathrm{L}$. The samples were incubated for 15 minutes and the fluorescence intensity was measured using a plate reader (CLARIOstar BMG Labtech). Excitation and emission spectra were $488 \mathrm{~nm}$ and $530 \mathrm{~nm}$, respectively.

\section{Immunofluorescence assays}

The following methods were used for measuring the PAR levels in live cells using confocal microscopy.

Tracking PAR in live cells. For live cell imaging assays to measure the level of PAR, HeLa cells expressing the fluorescence PAR-T sensors were plated on poly-D-Lysine coated live cell imaging chamber slides (Thermo Fisher, 15411) and cultured in FluoroBrite medium (Thermo Fisher, A1896701) supplemented with 10\% FBS (TET tested; Atlanta Biologicals, S103050) and $1 \%$ penicillin/streptomycin and $1 \mathrm{mg} / \mathrm{mL}$ of Dox. Twenty-four hours later, the cells were pretreated with $20 \mu \mathrm{M}$ PJ34 for 2 hours followed by treatment with $1 \mathrm{mM} \mathrm{H}_{2} \mathrm{O}_{2}$ for the indicated times. Images were acquired using an inverted Zeiss LSM 780 confocal microscope affixed with a $37^{\circ} \mathrm{C}, 5 \% \mathrm{CO} 2$ incubator.

Image analysis. We used Image $\mathrm{J}$ software to subtract background, set thresholds, select the regions of interest (ROIs), and quantify fluorescence intensity. The nuclei were selected using mCherry signal and corresponding intensity of PAR (GFP signal) was quantified. Time series v.3.0 plugin was used to get an average of the ROI intensities of mCherry and GFP.

Generation of $3 D$ cancer spheroids. For generation of cancer spheroids, MCF-7 cells expressing the fluorescence PAR-T sensors were sorted by fluorescence-activated cell sorting (FACS) to obtain a population of cells expressing high levels of mCherry (a marker for nuclei). The 3D cancer spheroids were then generated in Matrigel as described previously (Debnath et al., 2003) with some variations. The bottom of an 8-well chamber slide (Thermo Fisher, 154534) was coated with $90 \mu \mathrm{L}$ of $100 \%$ growth factor reduced Matrigel (Fisher, CB 40230) and incubated at $37^{\circ} \mathrm{C}$ for 30 minutes to allow the Matrigel to solidify. Then 5,000 cells in $400 \mu \mathrm{L}$ of complete Fluorobrite medium containing 2\% Matrigel was added on top of the Matrigel. The medium was changed every 3 days and the cells were allowed to grow for 2 weeks. Once the cells formed 3D clusters, expression of the PAR-T sensor was induced by treating the cells with $1 \mathrm{mg} / \mathrm{mL}$ Dox for 24 hours. For inhibition of PARylation, the cells were treated with $20 \mu \mathrm{M}$ Olaparib for 24 hours. Images of the 3D spheroids were acquired using LSM 880 confocal microscope. Multiple z-stacks were acquired and the Z-stack projections were obtained using Fiji Image J software.

\section{Luciferase assays}

Luciferase assays in live cells were performed to measure the levels of PAR in cells. Cells subjected to dox-inducible PAR-T expression were plated into black bottomed 96-well plates in the presence of $1 \mathrm{mg} / \mathrm{mL}$ Dox. Twenty-four hours later, the cells were treated as indicated and luciferase assays were performed using the Nano-Glo Live Cell Assay System (Promega, N2011) for Nanoluciferase measurements or by using the Luciferase assay system (Promega, E1500) for measuring firefly luciferase measurements according to the manufacturer's instructions. For dualluciferase assays, images of PAR-T Nanoluciferase were first obtained using the Nano-Glo Live 
Cell Assay System. The medium was then changed to PBS containing $100 \mu \mathrm{g} / \mathrm{mL}$ of D-luciferin (Gold Biotechnology, LUCNA-500) to obtain luminescence images of firefly luciferase. The luminescence images were obtained using IVIS Spectrum with an open filter. The luminescence intensities were quantified either by measuring the ROI intensities using IVIS Spectrum or by spectroscopy using a plate reader (CLARIOstar BMG Labtech).

\section{Xenograft experiments}

All mouse xenograft experiments were performed in compliance with the Institutional Animal Care and Use Committee (IACUC) at the UT Southwestern Medical Center. Female NOD/SCID/gamma (NSG) mice at 6-8 weeks of age were used. To establish breast cancer xenografts, $10 \times 10^{6}$ MDA-MB-231-Luc cells with Dox-inducible expression of PAR-T Nanoluciferase were injected subcutaneously in into the flank of the mice in $100 \mu \mathrm{L}$ of 1:1 ratio of PBS and Matrigel (Fisher, CB 40230). The weight of the mice and tumor growth was monitored once per week. Once the tumors were formed ( $\sim 3$ weeks post-tumor cell injection), the mice were randomized to receive $25 \mathrm{mg} / \mathrm{kg}$ of Niraparib or PARGi or vehicle in 4\% DMSO, 5\% PEG 300, $5 \%$ Tween80 in PBS intraperitoneally for 5 consecutive days a week ( 2 days off) for 3 weeks. The mice were placed on a Dox containing diet $(625 \mathrm{mg} / \mathrm{kg}$; Envigo) and injected with $100 \mu \mathrm{g} / \mathrm{g}$ of Dox for 5 days a week, for 3 weeks. Bioluminescence imaging of the xenografts was performed using IVIS Lumina. The mice were anesthetized, treated locally with 5 Gy of radiation, followed by injection in PBS of a combination of 40x dilutions of Nano-Glo live cell imaging (Promega, N2011) and Nano-Glo (Promega, N1110) substrates for acquiring Nanoluciferase luminescence. Luminescence from firefly luciferase was then measured by treating the mice with $150 \mathrm{mg} / \mathrm{kg} \mathrm{D}-$ Luciferin. 


\section{REFERENCES}

Ahel, I., Ahel, D., Matsusaka, T., Clark, A.J., Pines, J., Boulton, S.J., and West, S.C. (2008). Poly(ADP-ribose)-binding zinc finger motifs in DNA repair/checkpoint proteins. Nature 451, 8185.

Alford, S.C., Ding, Y., Simmen, T., and Campbell, R.E. (2012). Dimerization-dependent green and yellow fluorescent proteins. ACS Synth Biol 1, 569-575.

Ame, J.C., Spenlehauer, C., and de Murcia, G. (2004). The PARP superfamily. BioEssays : news and reviews in molecular, cellular and developmental biology 26, 882-893.

Barkauskaite, E., Jankevicius, G., Ladurner, A.G., Ahel, I., and Timinszky, G. (2013). The recognition and removal of cellular poly(ADP-ribose) signals. FEBS J 280, 3491-3507.

Bonfiglio, J.J., Leidecker, O., Dauben, H., Longarini, E.J., Colby, T., San Segundo-Acosta, P., Perez, K.A., and Matic, I. (2020). An HPF1/PARP1-based chemical biology strategy for exploring ADP-ribosylation. Cell 183, 1086-1102 e1023.

Bredehorst, R., Ferro, A.M., and Hilz, H. (1978). Production of antibodies against ADP-ribose and 5'-AMP with the aid of N6-carboxymethylated ADP-ribose conjugates. Eur J Biochem 82, 105113.

Challa, S., Stokes, M.S., and Kraus, W.L. (2021). MARTs and MARylation in the cytosol: biological functions, mechanisms of action, and therapeutic potential. Cells 10 .

Chen, Q., Kassab, M.A., Dantzer, F., and Yu, X. (2018). PARP2 mediates branched poly ADPribosylation in response to DNA damage. Nat Commun 9, 3233.

Dagogo-Jack, I., and Shaw, A.T. (2018). Tumour heterogeneity and resistance to cancer therapies. Nat Rev Clin Oncol 15, 81-94.

Daniels, C.M., Ong, S.E., and Leung, A.K. (2015). The promise of proteomics for the study of ADP-ribosylation. Mol Cell 58, 911-924.

Debnath, J., Muthuswamy, S.K., and Brugge, J.S. (2003). Morphogenesis and oncogenesis of MCF-10A mammary epithelial acini grown in three-dimensional basement membrane cultures. Methods 30, 256-268.

Dixon, A.S., Schwinn, M.K., Hall, M.P., Zimmerman, K., Otto, P., Lubben, T.H., Butler, B.L., Binkowski, B.F., Machleidt, T., Kirkland, T.A., et al. (2016). NanoLuc complementation reporter optimized for accurate measurement of protein interactions in cells. ACS Chem Biol 11, 400-408.

Feijs, K.L., Forst, A.H., Verheugd, P., and Luscher, B. (2013). Macrodomain-containing proteins: regulating new intracellular functions of mono(ADP-ribosyl)ation. Nat Rev Mol Cell Biol 14, 443451.

Forst, A.H., Karlberg, T., Herzog, N., Thorsell, A.G., Gross, A., Feijs, K.L., Verheugd, P., Kursula, P., Nijmeijer, B., Kremmer, E., et al. (2013). Recognition of mono-ADP-ribosylated ARTD10 substrates by ARTD8 macrodomains. Structure 21, 462-475.

Furman, J.L., Mok, P.W., Shen, S., Stains, C.I., and Ghosh, I. (2011). A turn-on split-luciferase sensor for the direct detection of poly(ADP-ribose) as a marker for DNA repair and cell death. Chem Commun (Camb) 47, 397-399. 
Gagne, J.P., Isabelle, M., Lo, K.S., Bourassa, S., Hendzel, M.J., Dawson, V.L., Dawson, T.M., and Poirier, G.G. (2008). Proteome-wide identification of poly(ADP-ribose) binding proteins and poly(ADP-ribose)-associated protein complexes. Nucleic Acids Res 36, 6959-6976.

Gibson, B.A., Conrad, L.B., Huang, D., and Kraus, W.L. (2017). Generation and characterization of recombinant antibody-like ADP-ribose binding proteins. Biochemistry 56, 6305-6316.

Gibson, B.A., and Kraus, W.L. (2012). New insights into the molecular and cellular functions of poly(ADP-ribose) and PARPs. Nat Rev Mol Cell Biol 13, 411-424.

Gupte, R., Liu, Z., and Kraus, W.L. (2017). PARPs and ADP-ribosylation: Recent advances linking molecular functions to biological outcomes. Genes Dev 31, 101-126.

Hall, M.P., Unch, J., Binkowski, B.F., Valley, M.P., Butler, B.L., Wood, M.G., Otto, P., Zimmerman, K., Vidugiris, G., Machleidt, T., et al. (2012). Engineered luciferase reporter from a deep sea shrimp utilizing a novel imidazopyrazinone substrate. ACS Chem Biol 7, 1848-1857.

Huang, D., Camacho, C.V., Setlem, R., Ryu, K.W., Parameswaran, B., Gupta, R.K., and Kraus, W.L. (2020). Functional Interplay between histone H2B ADP-ribosylation and phosphorylation controls adipogenesis. Mol Cell 79, 934-949 e914.

Kanai, Y., Miwa, M., Matsushima, T., and Sugimura, T. (1974). Studies on anti-poly(adenosine diphosphate ribose) antibody. Biochem Biophys Res Commun 59, 300-306.

Kanai, Y., Miwa, M., Matsushima, T., and Sugimura, T. (1978). Comparative studies on antibody and antibody production to poly(ADP-ribose) in mice. Immunology 34, 501-508.

Kang, H.C., Lee, Y.I., Shin, J.H., Andrabi, S.A., Chi, Z., Gagne, J.P., Lee, Y., Ko, H.S., Lee, B.D., Poirier, G.G., et al. (2011). Iduna is a poly(ADP-ribose) (PAR)-dependent E3 ubiquitin ligase that regulates DNA damage. Proceedings of the National Academy of Sciences of the United States of America 108, 14103-14108.

Karras, G.I., Kustatscher, G., Buhecha, H.R., Allen, M.D., Pugieux, C., Sait, F., Bycroft, M., and Ladurner, A.G. (2005). The macro domain is an ADP-ribose binding module. EMBO J 24, 19111920.

Kawamitsu, H., Hoshino, H., Okada, H., Miwa, M., Momoi, H., and Sugimura, T. (1984). Monoclonal antibodies to poly(adenosine diphosphate ribose) recognize different structures. Biochemistry 23, 3771-3777.

Krastev, D.B., Pettitt, S.J., Campbell, J., Song, F., Tanos, B.E., Stoynov, S.S., Ashworth, A., and Lord, C.J. (2018). Coupling bimolecular PARylation biosensors with genetic screens to identify PARylation targets. Nat Commun 9, 2016.

Lee, J.H., Ryu, S.W., Ender, N.A., and Paull, T.T. (2021). Poly-ADP-ribosylation drives loss of protein homeostasis in ATM and Mre11 deficiency. Mol Cell 81, 1515-1533 e1515.

Luker, K.E., Smith, M.C., Luker, G.D., Gammon, S.T., Piwnica-Worms, H., and Piwnica-Worms, D. (2004). Kinetics of regulated protein-protein interactions revealed with firefly luciferase complementation imaging in cells and living animals. Proceedings of the National Academy of Sciences of the United States of America 101, 12288-12293. 
Luo, X., Ryu, K.W., Kim, D.S., Nandu, T., Medina, C.J., Gupte, R., Gibson, B.A., Soccio, R.E., $\mathrm{Yu}$, Y., Gupta, R.K., et al. (2017). PARP-1 controls the adipogenic transcriptional program by PARylating C/EBP $\beta$ and modulating its transcriptional activity. Mol Cell 65, 260-271.

Luscher, B., Butepage, M., Eckei, L., Krieg, S., Verheugd, P., and Shilton, B.H. (2018). ADPribosylation, a multifaceted posttranslational modification involved in the control of cell physiology in health and disease. Chem Rev 118, 1092-1136.

Maita, H., Tomita, K., and Ariga, H. (2014). A split luciferase-based reporter for detection of a cellular macromolecular complex. Anal Biochem 452, 1-9.

Meyer, T., and Hilz, H. (1986). Production of anti-(ADP-ribose) antibodies with the aid of a dinucleotide-pyrophosphatase-resistant hapten and their application for the detection of mono(ADP-ribosyl)ated polypeptides. Eur J Biochem 155, 157-165.

Niere, M., Mashimo, M., Agledal, L., Dolle, C., Kasamatsu, A., Kato, J., Moss, J., and Ziegler, M. (2012). ADP-ribosylhydrolase 3 (ARH3), not poly(ADP-ribose) glycohydrolase (PARG) isoforms, is responsible for degradation of mitochondrial matrix-associated poly(ADP-ribose). J Biol Chem 287, 16088-16102.

Oka, S., Kato, J., and Moss, J. (2006). Identification and characterization of a mammalian 39-kDa poly(ADP-ribose) glycohydrolase. J Biol Chem 281, 705-713.

Pleschke, J.M., Kleczkowska, H.E., Strohm, M., and Althaus, F.R. (2000). Poly(ADP-ribose) binds to specific domains in DNA damage checkpoint proteins. J Biol Chem 275, 40974-40980.

Rack, J.G., Perina, D., and Ahel, I. (2016). Macrodomains: structure, function, evolution, and catalytic activities. Annu Rev Biochem 85, 431-454.

Ray Chaudhuri, A., and Nussenzweig, A. (2017). The multifaceted roles of PARP1 in DNA repair and chromatin remodelling. Nat Rev Mol Cell Biol 18, 610-621.

Ryu, K.W., Nandu, T., Kim, J., Challa, S., DeBerardinis, R.J., and Kraus, W.L. (2018). Metabolic regulation of transcription through compartmentalized $\mathrm{NAD}(+)$ biosynthesis. Science 360 .

Sakura, H., Miwa, M., Kanai, Y., Matsushima, T., and Sugimura, T. (1978). Formation and characterization of antibody against 2'-(5"-phosphoribosyl)-5' AMP, the monomer form of poly(adenosine diphosphate ribose). Nucleic Acids Res 5, 4025-4038.

Schaub, F.X., Reza, M.S., Flaveny, C.A., Li, W., Musicant, A.M., Hoxha, S., Guo, M., Cleveland, J.L., and Amelio, A.L. (2015). Fluorophore-nanoLuc BRET reporters enable sensitive in vivo optical imaging and flow cytometry for monitoring tumorigenesis. Cancer Res 75, 5023-5033.

Serebrovskaya, E.O., Podvalnaya, N.M., Dudenkova, V.V., Efremova, A.S., Gurskaya, N.G., Gorbachev, D.A., Luzhin, A.V., Kantidze, O.L., Zagaynova, E.V., Shram, S.I., et al. (2020). Genetically encoded fluorescent sensor for poly-ADP-Ribose. Int J Mol Sci 21.

Slade, D., Dunstan, M.S., Barkauskaite, E., Weston, R., Lafite, P., Dixon, N., Ahel, M., Leys, D., and Ahel, I. (2011). The structure and catalytic mechanism of a poly(ADP-ribose) glycohydrolase. Nature 477, 616-620.

Teloni, F., and Altmeyer, M. (2016). Readers of poly(ADP-ribose): designed to be fit for purpose. Nucleic Acids Res 44, 993-1006. 
Timinszky, G., Till, S., Hassa, P.O., Hothorn, M., Kustatscher, G., Nijmeijer, B., Colombelli, J., Altmeyer, M., Stelzer, E.H., Scheffzek, K., et al. (2009). A macrodomain-containing histone rearranges chromatin upon sensing PARP1 activation. Nature structural \& molecular biology 16, 923-929.

Tung, J.K., Berglund, K., Gutekunst, C.A., Hochgeschwender, U., and Gross, R.E. (2016). Bioluminescence imaging in live cells and animals. Neurophotonics 3, 025001.

Villalobos, V., Naik, S., and Piwnica-Worms, D. (2007). Current state of imaging protein-protein interactions in vivo with genetically encoded reporters. Annu Rev Biomed Eng 9, 321-349.

Vyas, S., Chesarone-Cataldo, M., Todorova, T., Huang, Y.H., and Chang, P. (2013). A systematic analysis of the PARP protein family identifies new functions critical for cell physiology. Nat Commun 4, 2240.

Wang, F.Z., Zhang, N., Guo, Y.J., Gong, B.Q., and Li, J.F. (2020). Split Nano luciferase complementation for probing protein-protein interactions in plant cells. J Integr Plant Biol 62, 1065-1079.

Wang, Z., Michaud, G.A., Cheng, Z., Zhang, Y., Hinds, T.R., Fan, E., Cong, F., and Xu, W. (2012). Recognition of the iso-ADP-ribose moiety in poly(ADP-ribose) by WWE domains suggests a general mechanism for poly(ADP-ribosyl)ation-dependent ubiquitination. Genes Dev 26, 235240.

Yano, H., Cai, N.S., Javitch, J.A., and Ferre, S. (2018). Luciferase complementation baseddetection of G-protein-coupled receptor activity. Biotechniques 65, 9-14.

Zhang, Y., Liu, S., Mickanin, C., Feng, Y., Charlat, O., Michaud, G.A., Schirle, M., Shi, X., Hild, M., Bauer, A., et al. (2011). RNF146 is a poly(ADP-ribose)-directed E3 ligase that regulates axin degradation and Wnt signalling. Nature cell biology 13, 623-629. 
Table 1. Nomenclature, composition, and activity of the various PAR-T sensors used in this study.

A summary of the PAR-Tracker sensors generated in this study. The activity of these sensors in in vitro and in cells, and the corresponding figures in which the activities are described, are indicated. The activities are described as low $(+)$, medium $(++)$, and high $(+++,++++)$. N.D. not determined.

\begin{tabular}{|c|c|c|c|c|c|}
\hline \multirow{2}{*}{\begin{tabular}{|c|}
$\begin{array}{c}\text { Nomenclature } \\
\text { used in the } \\
\text { manuscript }\end{array}$ \\
$\begin{array}{c}\text { Fluorescent } \\
\text { sensors }\end{array}$ \\
\end{tabular}} & \multicolumn{2}{|c|}{$\begin{array}{l}\text { ARBDs used with fluorescent } \\
\text { or luminescent protein fragments }\end{array}$} & \multirow[t]{2}{*}{$\begin{array}{l}\text { Activity } \\
\text { in vitro }\end{array}$} & \multirow[t]{2}{*}{$\begin{array}{l}\text { Activity } \\
\text { in cells } \\
\end{array}$} & \multirow[t]{2}{*}{ Figures } \\
\hline & ddGFP-A & ddGFP-B & & & \\
\hline \multirow[t]{6}{*}{ PAR-T GFP } & WWE from RNF146 & WWE from RNF146 & +++ & ++++ & $\begin{array}{l}\text { Figure 1- figure } \\
\text { supplement } 1 \mathrm{D}, \mathrm{E}\end{array}$ \\
\hline & $\begin{array}{l}\text { Macrodomain from } \\
\text { AF1521 } \\
\end{array}$ & $\begin{array}{l}\text { Macrodomain from } \\
\text { AF1521 }\end{array}$ & ++ & N.D. & $\begin{array}{l}\text { Figure 1- figure } \\
\text { supplement 1D, E }\end{array}$ \\
\hline & PBZ from APLF & PBZ from APLF & + & N.D. & $\begin{array}{l}\text { Figure 1- figure } \\
\text { supplement 1D, E }\end{array}$ \\
\hline & $\begin{array}{l}\text { Macrodomain from } \\
\text { MH2A.1 }\end{array}$ & $\begin{array}{l}\text { Macrodomain from } \\
\text { MH2A.1 }\end{array}$ & + & N.D. & $\begin{array}{l}\text { Figure 1- figure } \\
\text { supplement 1D, E }\end{array}$ \\
\hline & WWE from RNF146 & $\begin{array}{l}\text { Macrodomain from } \\
\text { AF1521 }\end{array}$ & +++ & N.D. & $\begin{array}{l}\text { Figure 1- figure } \\
\text { supplement 1D, E }\end{array}$ \\
\hline & $\begin{array}{l}\text { Macrodomain from } \\
\text { AF1521 }\end{array}$ & WWE from RNF146 & ++++ & - & $\begin{array}{l}\text { Figure 1- figure } \\
\text { supplement 1D, E }\end{array}$ \\
\hline $\begin{array}{c}\text { Firefly } \\
\text { luciferase- } \\
\text { based sensors }\end{array}$ & $\begin{array}{l}\text { N-terminal of Firefly } \\
\text { luciferase (FLucN) }\end{array}$ & $\begin{array}{l}\text { C-terminal of Firefly } \\
\text { luciferase (FLucC) }\end{array}$ & & & \\
\hline \multirow[t]{4}{*}{ PAR-T fLuc } & WWE from RNF146 & WWE from RNF146 & N.D. & + & $\begin{array}{l}\text { Figure } 3 \text { - figure } \\
\text { supplement } 1 \mathrm{C}\end{array}$ \\
\hline & $\begin{array}{l}\text { Macrodomain from } \\
\text { AF1521 }\end{array}$ & $\begin{array}{l}\text { Macrodomain from } \\
\text { AF1521 }\end{array}$ & N.D. & - & $\begin{array}{c}\text { Figure } 3 \text { - figure } \\
\text { supplement } 1 \mathrm{C}\end{array}$ \\
\hline & WWE from RNF146 & $\begin{array}{l}\text { Macrodomain from } \\
\text { AF1521 }\end{array}$ & N.D. & - & $\begin{array}{l}\text { Figure } 3 \text { - figure } \\
\text { supplement } 1 \mathrm{C}\end{array}$ \\
\hline & $\begin{array}{l}\text { Macrodomain from } \\
\text { AF1521 }\end{array}$ & WWE from RNF146 & N.D. & - & $\begin{array}{c}\text { Figure } 3 \text { - figure } \\
\text { supplement } 1 \mathrm{C}\end{array}$ \\
\hline $\begin{array}{c}\text { Nano } \\
\text { luciferase- } \\
\text { based sensors } \\
\end{array}$ & $\begin{array}{c}\text { N-terminal of Nano } \\
\text { luciferase (NanoLucN) }\end{array}$ & $\begin{array}{c}\text { C-terminal of Nano } \\
\text { luciferase plus } \\
\text { LssmOrange } \\
\text { (NanoLucC) } \\
\end{array}$ & & & \\
\hline PAR-T Luc & WWE from RNF146 & WWE from RNF146 & N.D. & ++++ & Figure 3B \\
\hline
\end{tabular}




\section{Main Figures}

A

Poly(ADP-ribose)-dependent Fluorescence

(D) PAR binding Domain (A) ddGFPA (B) ddGFPB

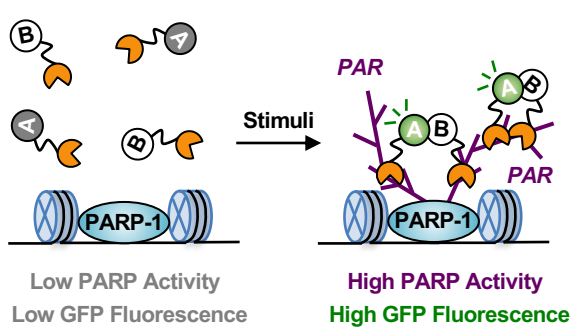

C

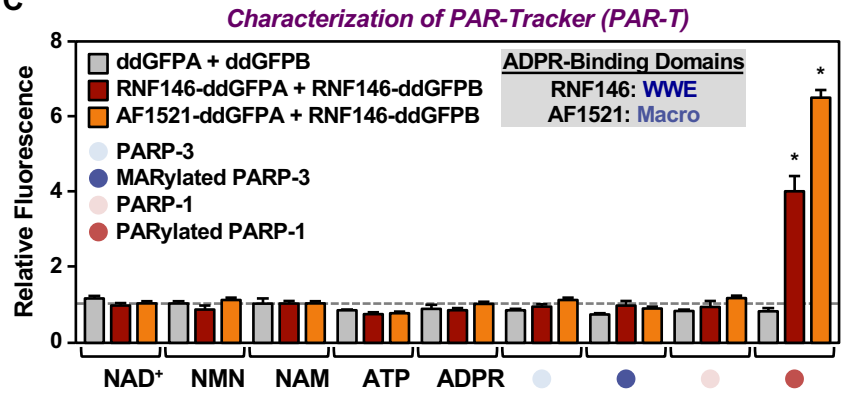

E

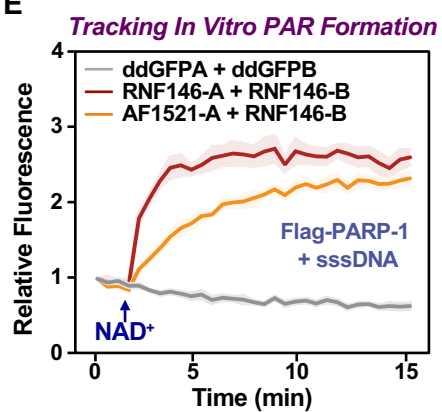

B

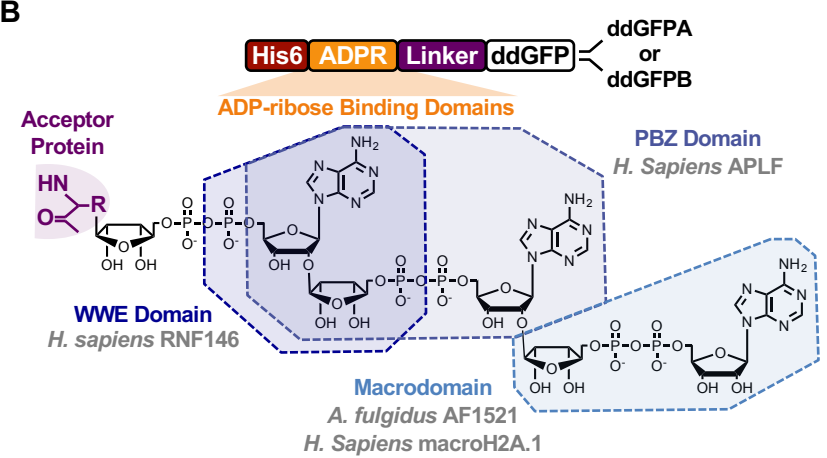

D

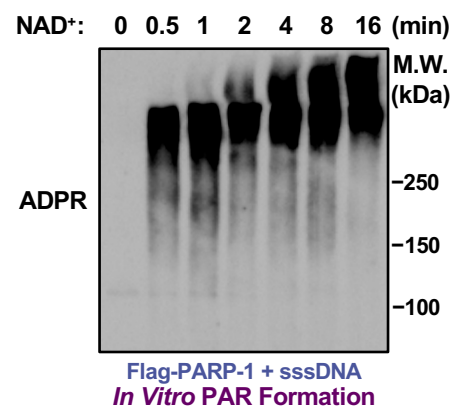

G Tracking In Vitro PAR Degradation

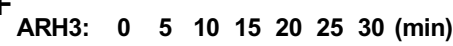

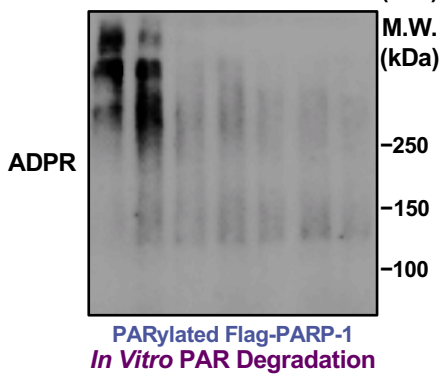

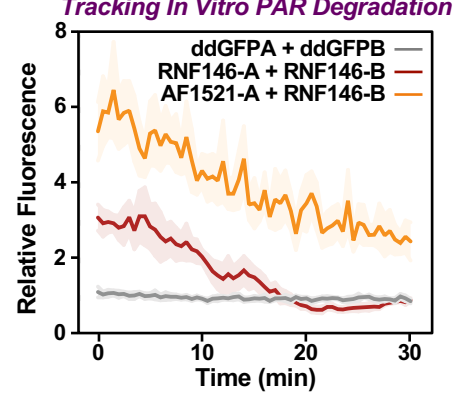

Figure 1. Development of ddGFP-based fluorescent sensors to measure PAR levels.

(A) Schematic diagram of the fluorescent PAR trackers (PAR-Ts).

(B) Schematic diagram of the plasmid constructs used to express the ddGFP PAR-T in bacteria. Chemical structures of a PARylated amino acid, a MARylated amino acid, and the chemical moieties in ADPR that are recognized by the ADPR binding domains. The constructs contain DNA segments encoding (1) His tag (red), (2) ADP-ribose binding domain (yellow), (3) a flexible linker (purple), and (4) ddGFP proteins (white).

(C) Verification of substrate specificity. Fluorescence measurements of in vitro ADPRylation assays containing the indicated substrates. Each bar in the graph represents the mean \pm SEM of the relative fluorescence intensity ( $\mathrm{n}=3$, Two-way ANOVA, $* \mathrm{p}<0.0001)$.

(D and E) Western blot analysis (D) and fluorescence measurements (E) of the time course of in vitro PAR formation using recombinant PARP-1. Each line plot in the graph in (E) represents mean \pm SEM of relative fluorescence intensity $(\mathrm{n}=3)$.

(F and G) Western blot analysis (F) and fluorescence measurements (G) of the time course of in vitro PAR degradation using recombinant ARH3. Each line plot in the graph in $(\mathrm{G})$ represents mean \pm SEM of relative fluorescence intensity $(n=3)$. 
A

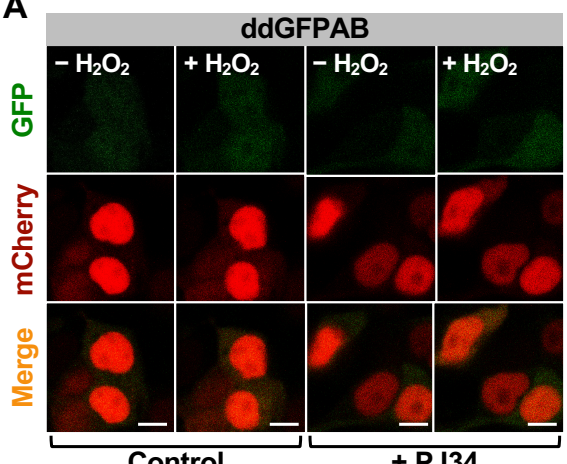

Control

C

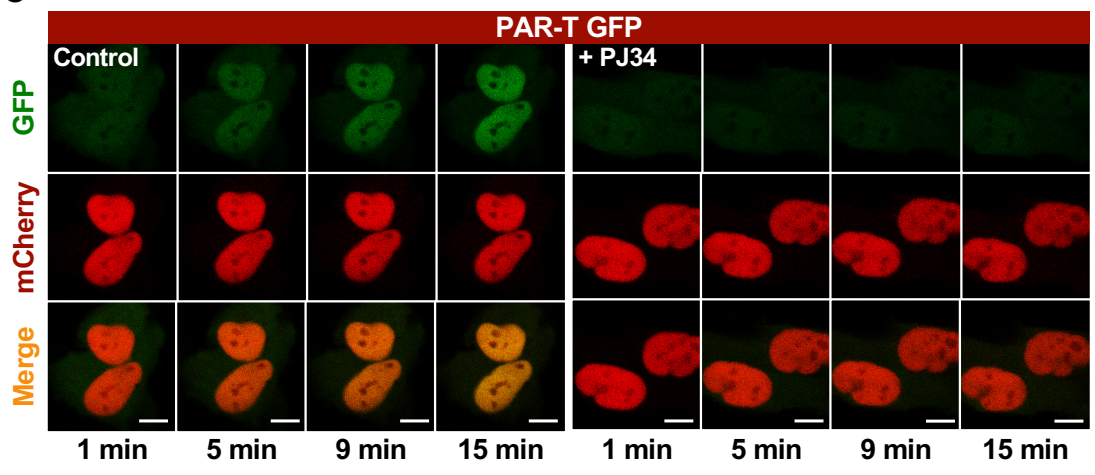

B
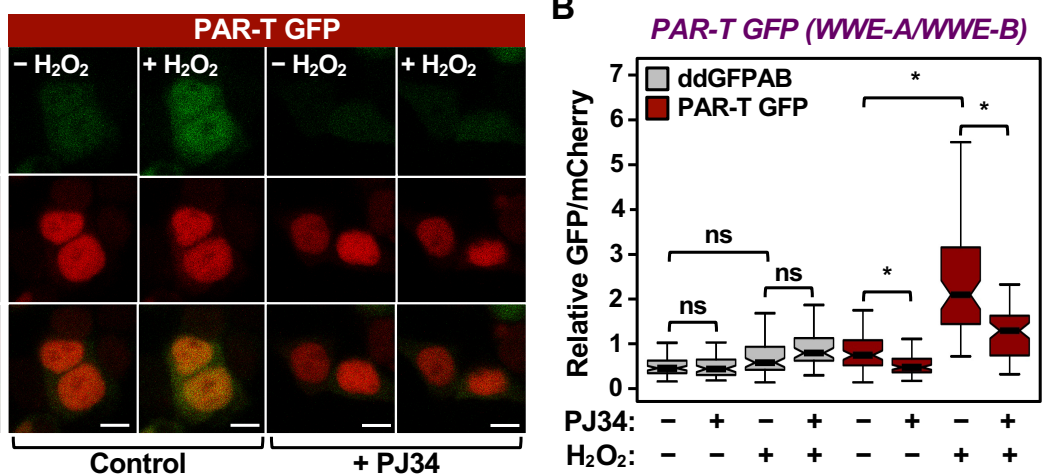

D

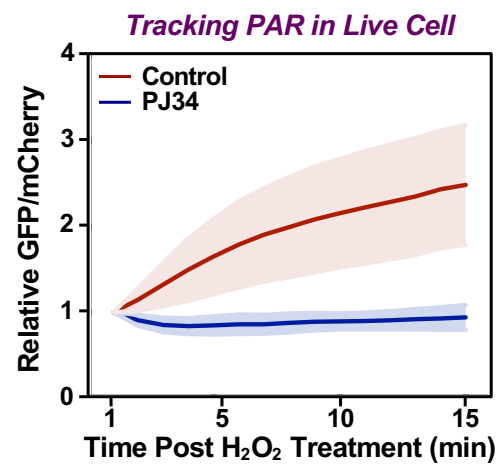

Figure 2. Tracking PAR accumulation in live cells using PAR-T GFP.

(A and B) Immunofluorescence assay to track PAR formation in response to $\mathrm{H}_{2} \mathrm{O}_{2}$ using 293T cells subjected to Dox-induced PAR-T GFP expression. The cells were treated with $20 \mu \mathrm{M}$ PJ34 for 2 hours prior to $\mathrm{H}_{2} \mathrm{O}_{2}$ treatment. The scale bar is $10 \mu \mathrm{m}$. Each bar in the graph in (B) represents the mean \pm SEM of the relative levels of the fluorescence intensity $(n=3$, One-way ANOVA, $* p$ $<0.01)$.

(C and D) Live cell tracking of PAR formation in response to $\mathrm{H}_{2} \mathrm{O}_{2}$. HeLa cells subjected to PART GFP expression were treated with $20 \mu \mathrm{M}$ PJ34 for 2 hours prior to $\mathrm{H}_{2} \mathrm{O}_{2}$ treatment and live cell imaging. The scale bar is $10 \mu \mathrm{m}$. Each bar in the graph in (D) represents the mean $\pm \mathrm{SD}$ of the relative levels of the fluorescence intensity $(n=20$ for control and $n=21$ for PJ34). 
A
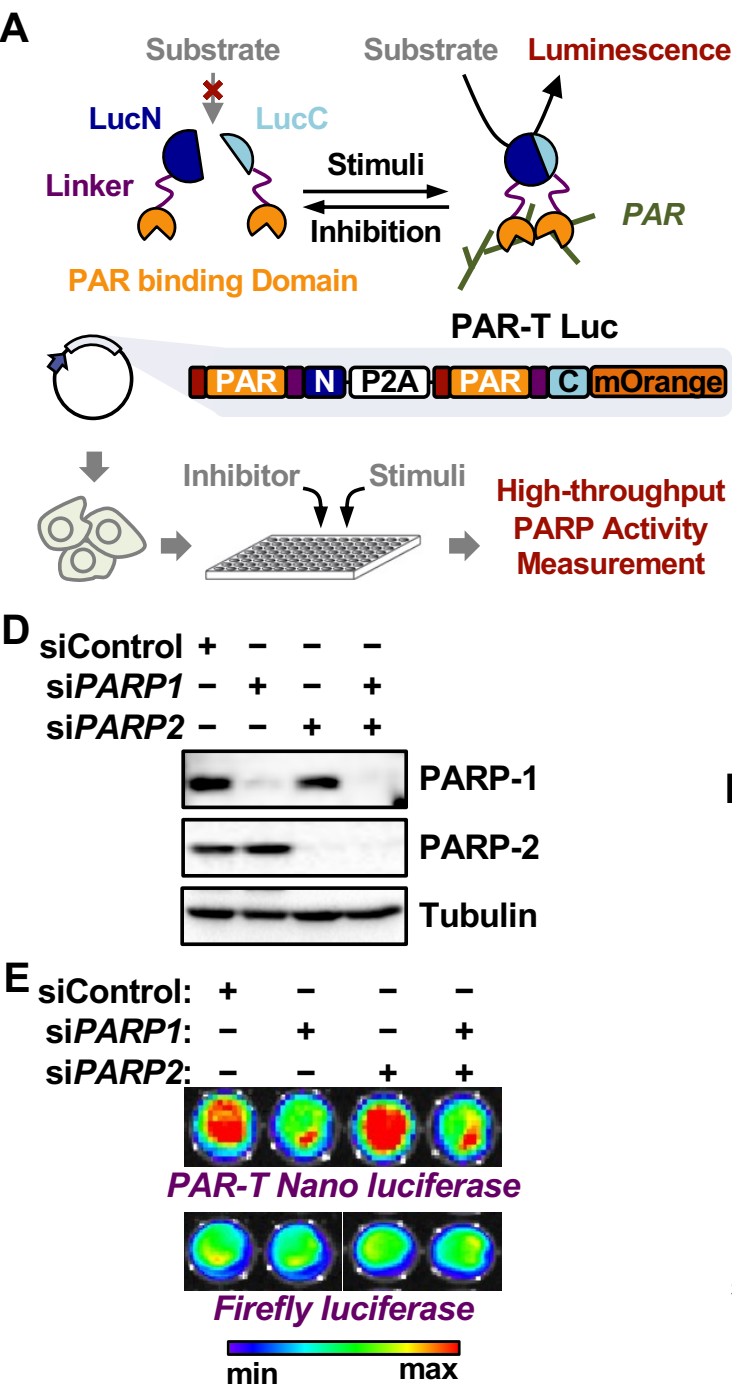

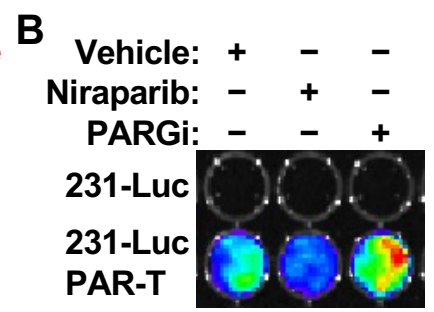

PAR-T Nano luciferase

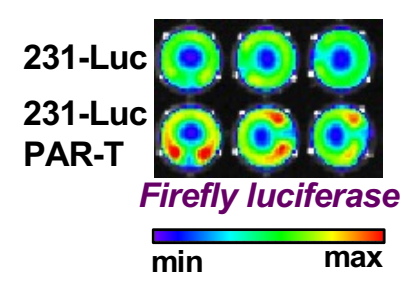

$\mathbf{F}$

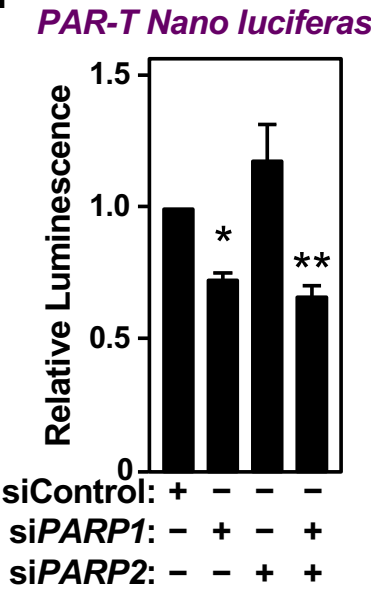

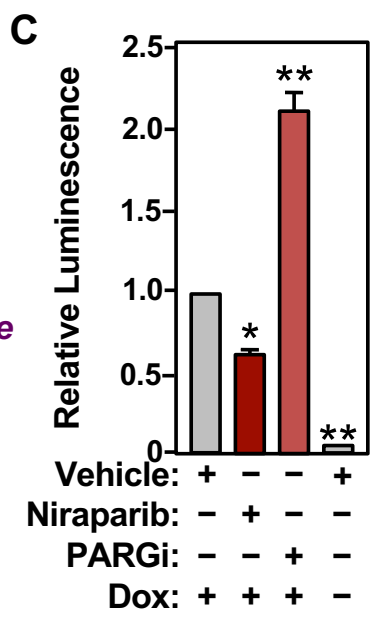

Firefly luciferase

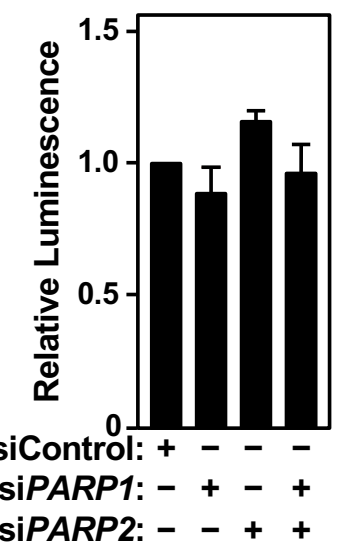

Figure 3. Development of luminescent sensors to measure PAR levels.

(A) Schematic diagram of the plasmid constructs used to express the split Nano luciferase PARTracker (PAR-T Luc) in mammalian cells. The constructs contain DNA segments encoding (1) Flag tag (red), (2) ADP-ribose binding domain (yellow), (3) a flexible linker (purple), and (4) the N-terminal (dark blue) or C-terminal (light blue) fragments of NanoLuc.

(B and C) Bioluminescence imaging (B) of MDA-MB-231-luc cells subjected to Dox-induced expression of PAR-T Luc (231-PAR-T Nluc). The cells were treated with $20 \mu \mathrm{M}$ Niraparib or 20 $\mu \mathrm{M}$ PARG inhibitor (PDD00017273) for 2 hours prior to bioluminescence imaging. Each bar in the graph in (C) represents the mean $\pm \mathrm{SEM}$ of the relative levels of the ratio of luminescence of NanoLuc to firefly luciferase $\left(\mathrm{n}=3\right.$, Two-way ANOVA, ${ }^{*} \mathrm{p}<0.01$ and $\left.* * \mathrm{p}<0.0001\right)$.

(D) Western blot analysis of MDA-MB-231-luc cells subjected to siRNA mediated knockdown of PARP1 or PARP2.

(E and F) Bioluminescence measurement (E) of 231-PAR-T Nluc cells subjected to PARP1 or $P A R P 2$ knockdown. Each bar in the graph in (F) represents the mean $\pm \mathrm{SEM}$ of the relative levels of luminescence of NanoLuc or firefly luciferase $(\mathrm{n}=3$, t-test, $* \mathrm{p}<0.05$ and $* * \mathrm{p}<0.01)$. 

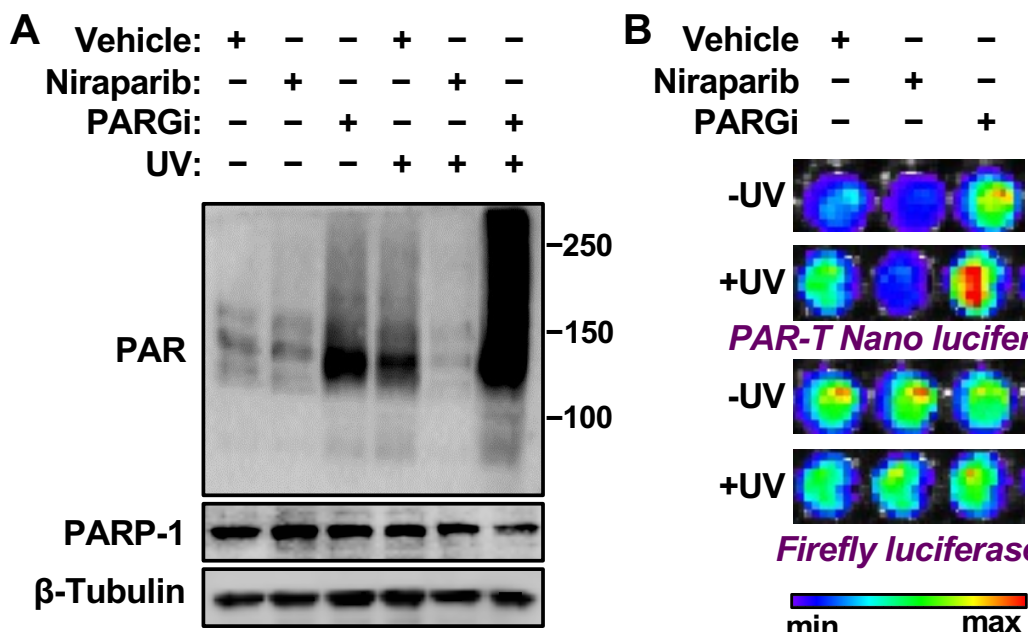

PAR-T Nano luciferase
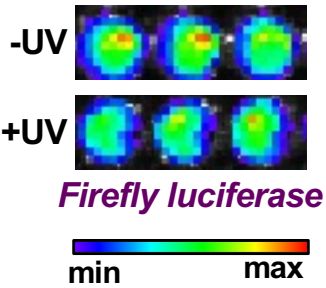

C

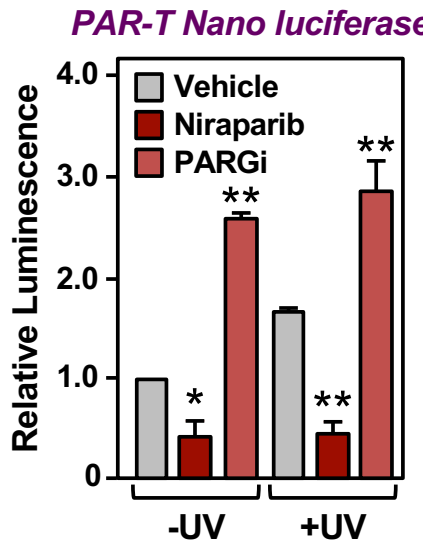

Figure 4. Tracking PAR accumulation in response to UV-induced DNA damage using PART Luc

(A) Western blot analysis of 231-PAR-T Luc cells treated with Niraparib or PARG inhibitor prior to $\mathrm{UV}$ radiation.

(B and C) Bioluminescence imaging (B) of 231-PAR-T Nluc cells treated with $20 \mu \mathrm{M}$ Niraparib or $20 \mu \mathrm{M}$ PARG inhibitor for 2 hours prior to UV radiation. Each bar in the graph in (C) represents the mean \pm SEM of the relative levels of luminescence of NanoLuc or firefly luciferase $(n=3$, Two-way ANOVA, $* \mathrm{p}<0.05$ and $* * \mathrm{p}<0.01)$. 
A

PAR-T Nano luciferase

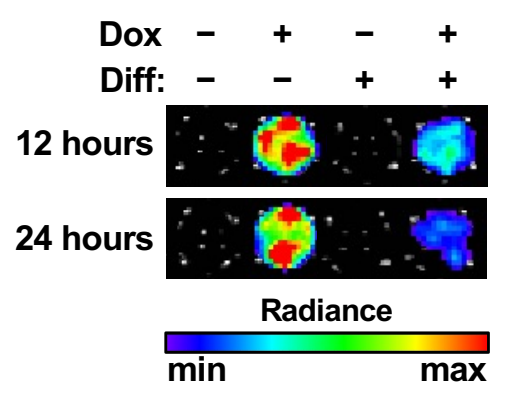

B

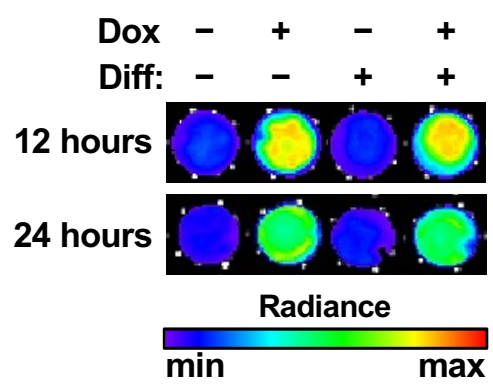

C

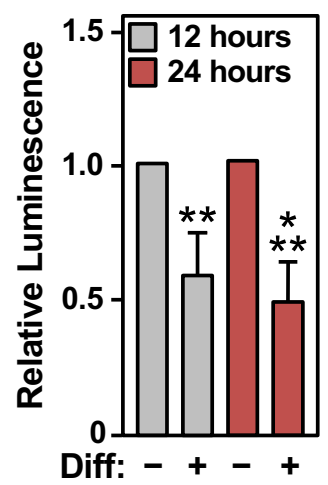

Figure 5. Tracking the levels of PAR during adipogenesis.

(A and B) Bioluminescence imaging of PAR-T Luc (A) and unsplit NanoLuc (B) in 3T3-L1 cells subjected to adipogenic differentiation for 12 hours or 24 hours.

(C) Quantification of signals from PAR-T Luc during adipogenesis. Each bar in the graph in (C) represents the mean \pm SEM of the relative levels of the ratio of luminescence of NanoLuc $(n=4$; t-test, $* * \mathrm{p}<0.01$ and $* * * \mathrm{p}<0.001)$. 
A

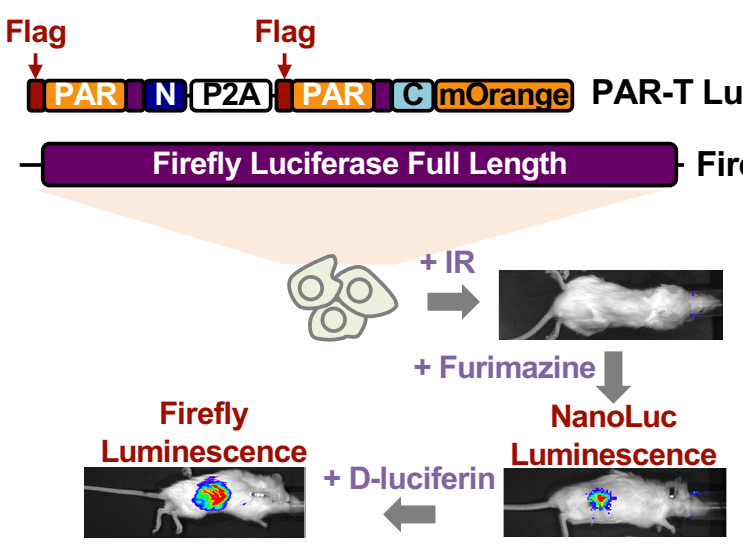

C

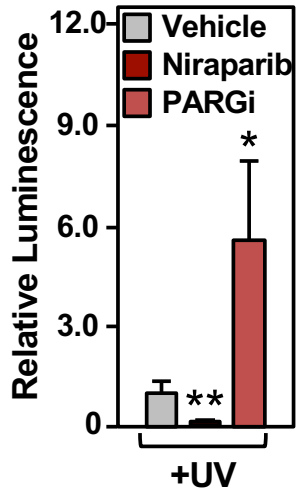

B

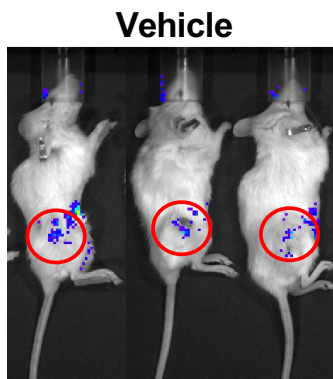

Niraparib
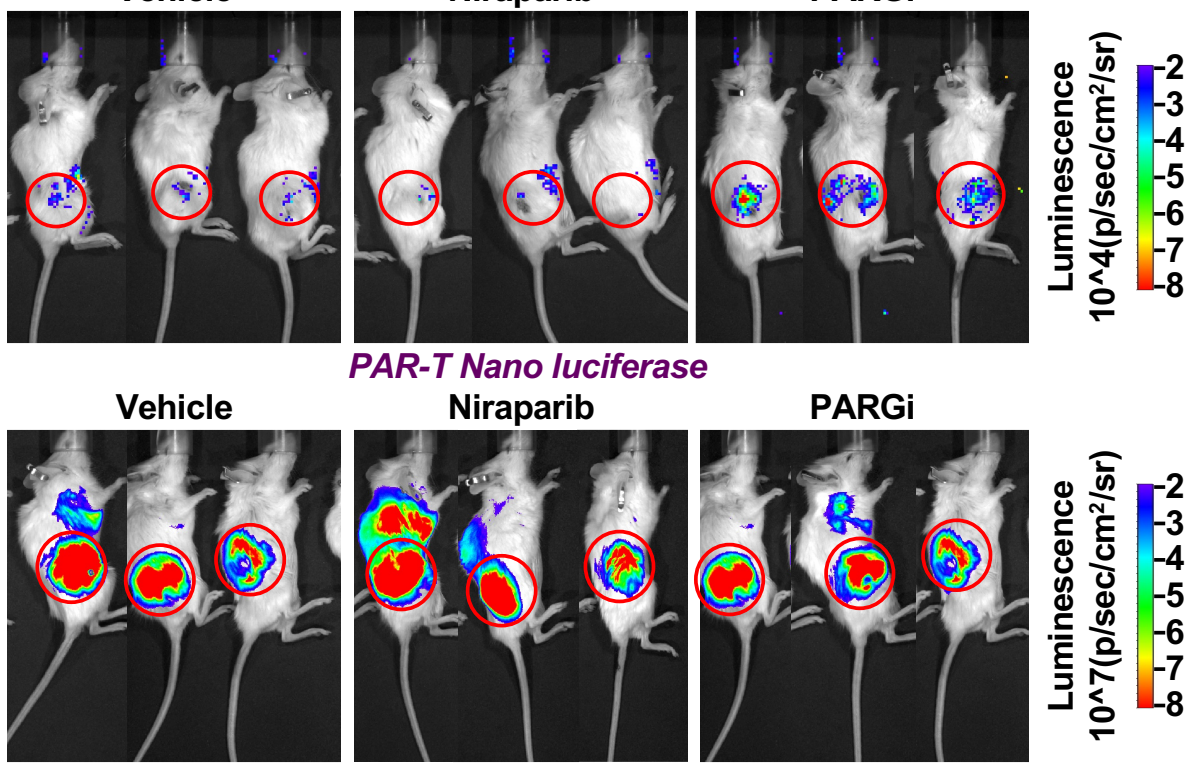

PAR-T Nano luciferase Niraparib

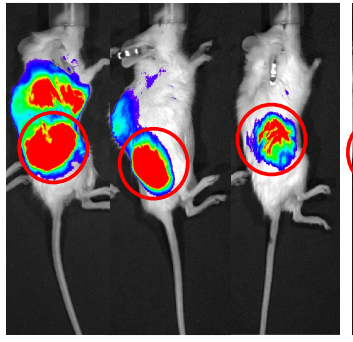

PARGi
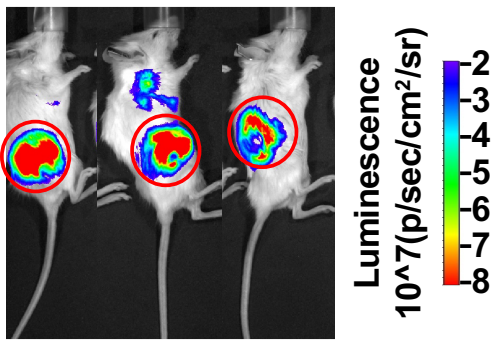

Firefly luciferase

Figure 6. Tracking the levels of PAR in tissues in living animals using PAR-T Luc. (A) Schematic diagram of the in vivo studies performed using 231-PAR-T Luc cells. (B and C) Bioluminescence imaging (B) of tumors formed using 231-PAR-T Nluc cells. The tumors were subjected to 5 Gy IR radiation prior to BLI imaging. Each bar in the graph in (C) represents the mean \pm SEM of the relative levels of the ratio of luminescence of NanoLuc to firefly luciferase ( $n=6$ for the vehicle and PARG inhibitor treatment cohorts and $n=7$ for the Niraparib treatment cohort; t-test, ${ }^{*} \mathrm{p}<0.05$ and $\left.* * \mathrm{p}<0.01\right)$. 
FiguRE SUPPLEMENTS

[Figure 1 - figure supplement 1 is on the next page]

Figure 1 - figure supplement 1. Characterization of fluorescence-based PAR-Trackers using biochemical assays.

(A) SDS-PAGE with Coomassie brilliant blue staining of recombinant ddGFP PAR-Trackers with the indicated ADPR binding domains.

(B) SDS-PAGE with Coomassie brilliant blue staining of recombinant Flag-tagged PARP-1 and PARP-3 proteins.

(C) In vitro auto(ADP-ribosyl)ation reactions using recombinant PARP-1 and PARP-3 proteins from (B).

(D and E) Fluorescence measurements (D) and heatmap (E) of in vitro PARylation detection assays performed using the indicated PAR-binding domains.

(F and G) Western blot analysis (F) and fluorescence measurements $(\mathrm{G})$ of in vitro PAR formation using recombinant PARP-1 and the indicated concentrations of $\mathrm{NAD}^{+}$. Each line in the graph in (G) represents the mean \pm SEM of the relative fluorescence intensity $(n=3)$.

(H) Fluorescence measurements of in vitro PAR degradation using the indicated concentrations of recombinant ARH3. Each line plot in the graph represents the mean $\pm \mathrm{SEM}$ of the relative fluorescence intensity $(\mathrm{n}=3)$.

(I and J) Western blot analysis (I) and fluorescence measurements (J) of PAR in HeLa cell extracts using recombinant ddGFP proteins. The cells were treated with $20 \mu \mathrm{M}$ PJ34 or $20 \mu \mathrm{M}$ PARGi for 2 hours before lysis. Each bar in the graph in $(\mathrm{J})$ represents the mean \pm SEM of the relative fluorescence intensity $(\mathrm{n}=3$, Two-way ANOVA * $\mathrm{p}<0.05)$. 
Figure 1 - figure supplement 1.

A

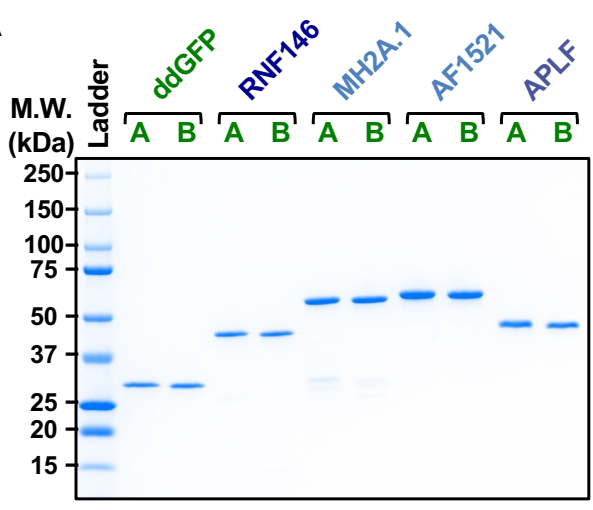

ADPR-binding Domain: WWE / Macro / PBZ

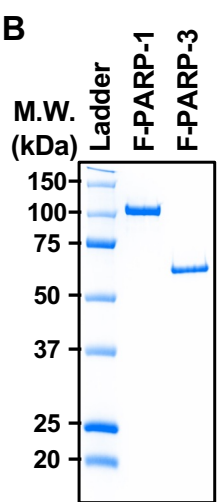

$\mathbf{F}$
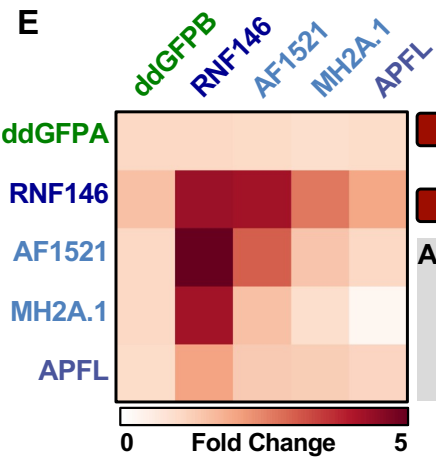

H

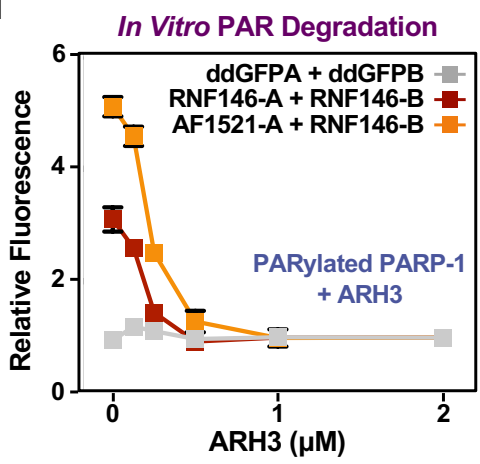

I

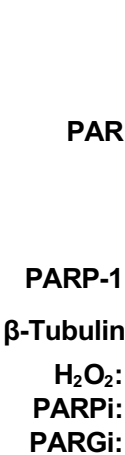

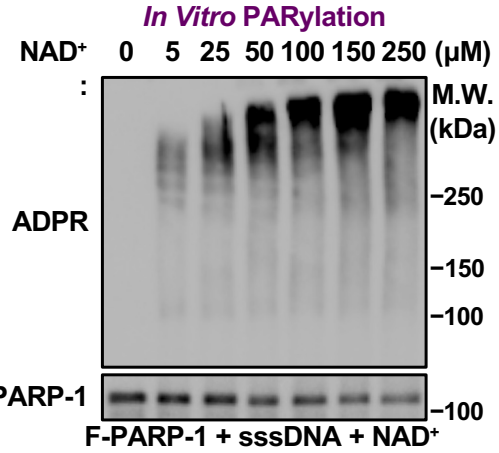

D PARP-3

MARylated PARP-3

PARP-1

PARylated PARP-1

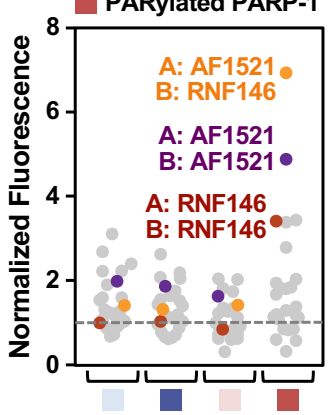

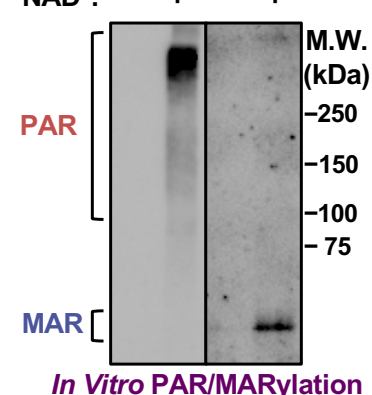

G

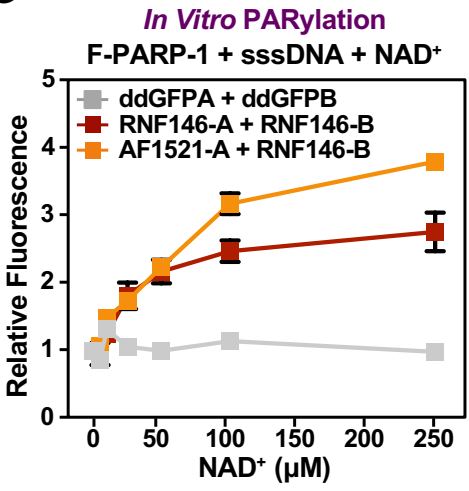

HeLa Cell Lysate
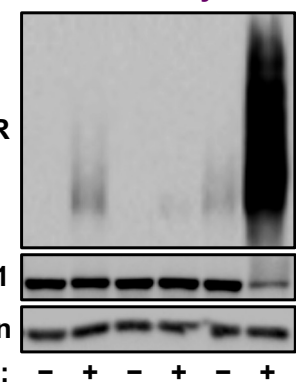

J PAR Detection in HeLa Cell Lysate

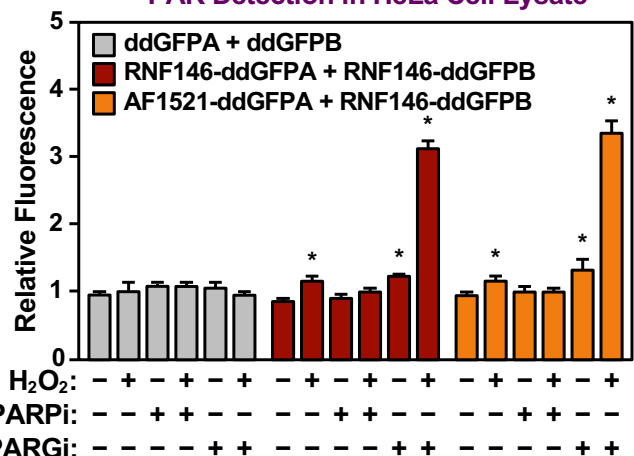




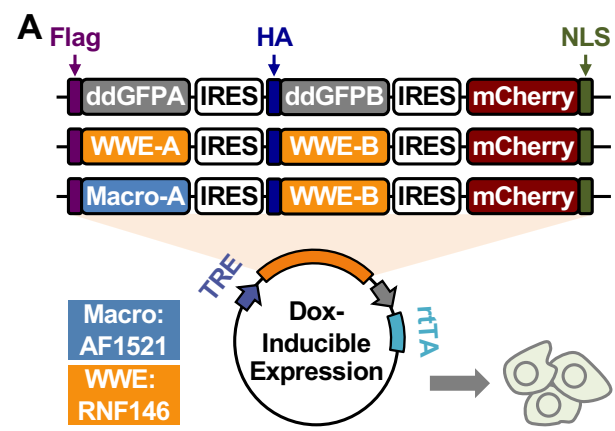

B

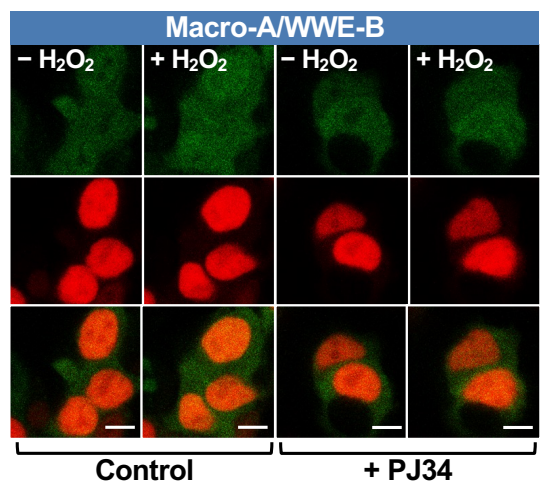

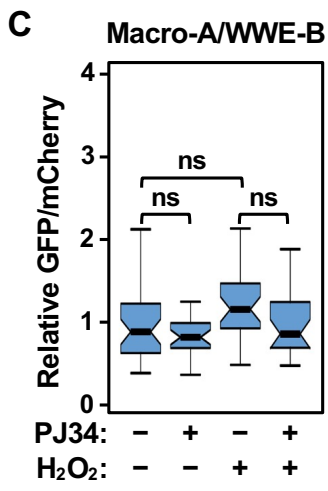

Figure 2 - figure supplement 1. Characterization of fluorescence-based PAR-Trackers using live cell imaging.

(A) Schematic diagram of plasmid constructs used to express PAR-T GFP in mammalian cells. The constructs contain DNA segments encoding (1) Flag (purple) or HA (dark blue) tags to allow detection of the ddGFPA or ddGFPB protein fragments respectively, (2) ddGFP-conjugated ADPribose binding domains, WWE (yellow) or Macrodomain (light blue), (3) IRES (white), (4) mCherry (red), and (5) nuclear localization signal (green).

(B and C) Immunofluorescence assay to track PAR formation in response to $\mathrm{H}_{2} \mathrm{O}_{2}$. 293T cells subjected to Dox-induced expression of the sensors were treated with $20 \mu \mathrm{M}$ PJ34 for 2 hours prior to $\mathrm{H}_{2} \mathrm{O}_{2}$ treatment. (B) Detection by microscopy. The scale bar is $10 \mu \mathrm{m}$. (C) Each bar in the graph represents the mean \pm SEM of the relative levels of the fluorescence intensities (One-way ANOVA). 


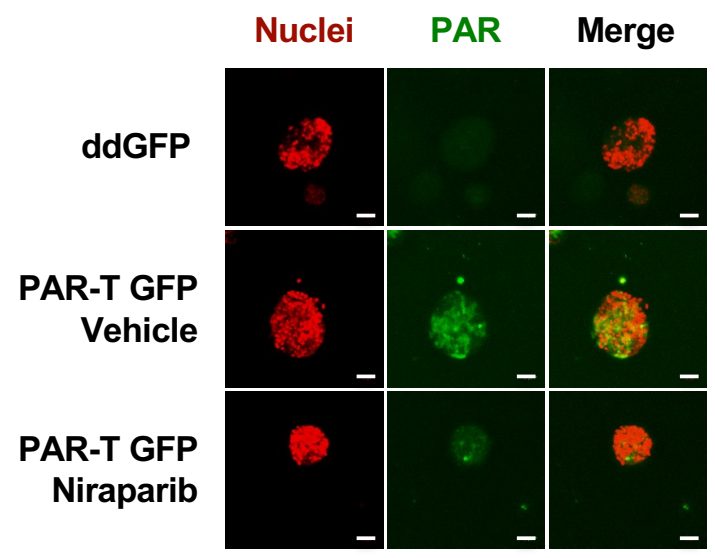

Figure 2 - figure supplement 2. Spatially tracking PAR formation using PAR-T GFP.

Representative images of Z-projections of cancer spheroids formed using MCF-7 cells subjected to Dox-induced expression of the PAR-T GFP. The spheroids were treated with $20 \mu \mathrm{M}$ Niraparib for 24 hours prior to imaging. The scale bar is $50 \mu \mathrm{m}$. 
A

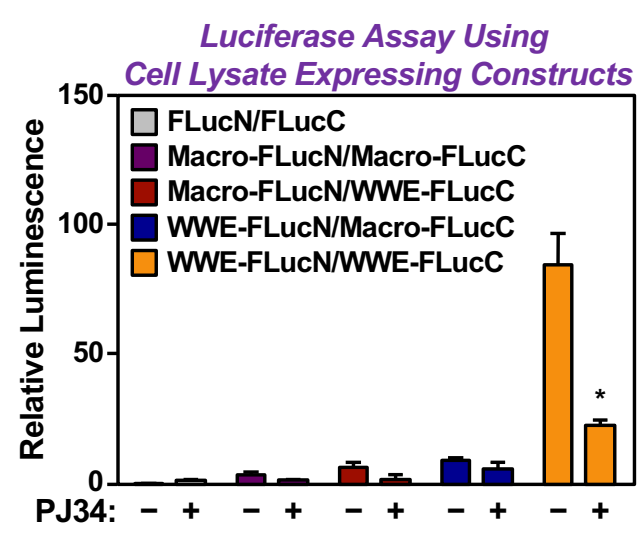

B

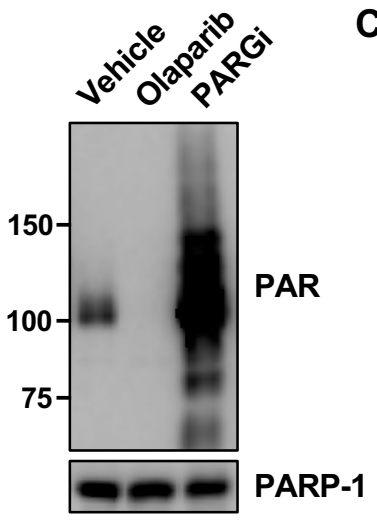

C

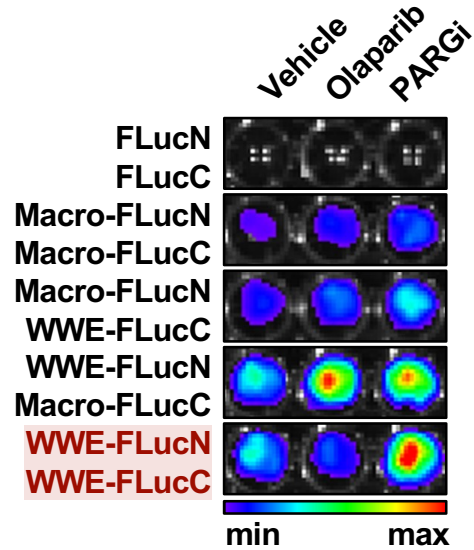

D

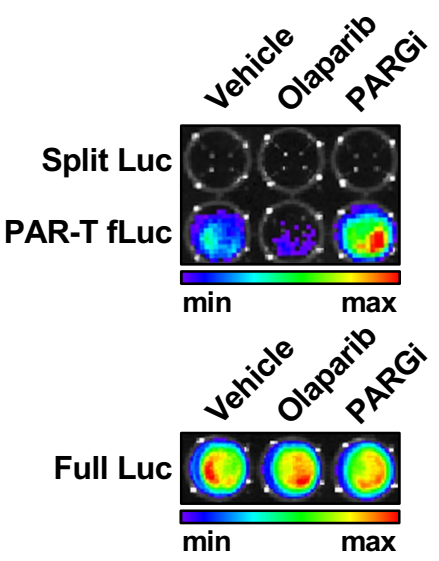

E

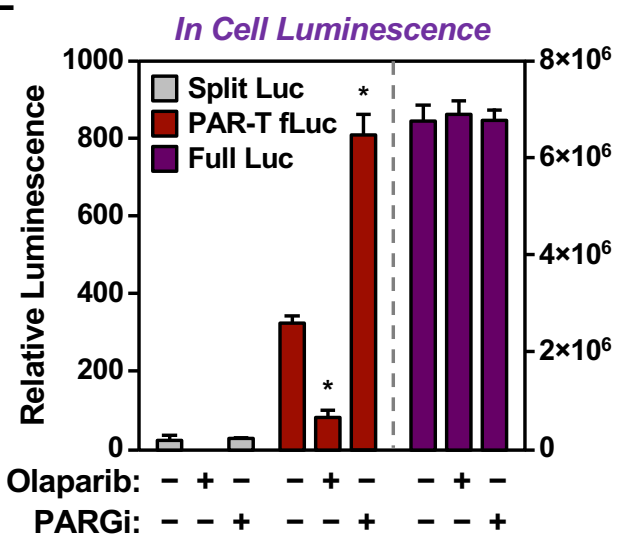

Figure 3 - figure supplement 1. Characterization of a luminescence-based PAR-Tracker. (A) Quantitative bioluminescence imaging of cell extracts isolated from HEK 293T cells subjected to expression of the indicated PAR binding domains conjugated to split firefly luciferase fragments. The cells were treated with $20 \mu \mathrm{M}$ PJ34 for 2 hours prior to lysis.

(B) Western blot analysis of lysates from HEK 293T cells treated with $20 \mu \mathrm{M}$ Olaparib or $20 \mu \mathrm{M}$ PARGi.

(C) Bioluminescence imaging HEK 293T cells subjected to expression of the indicated split firefly luciferase protein fragments.

(D and E) Bioluminescence imaging (D) of HeLa cells subjected to expression of the indicated split firefly luciferase protein fragments. The cells were treated with $20 \mu \mathrm{M}$ Olaparib or $20 \mu \mathrm{M}$ PARGi for 2 hours prior to bioluminescence imaging. Each bar in the graph in (E) represents the mean \pm SEM of the relative levels of luminescence $(n=3$, Two-way ANOVA $* p<0.01$ and $* *$ $\mathrm{p}<0.0001)$. 
A

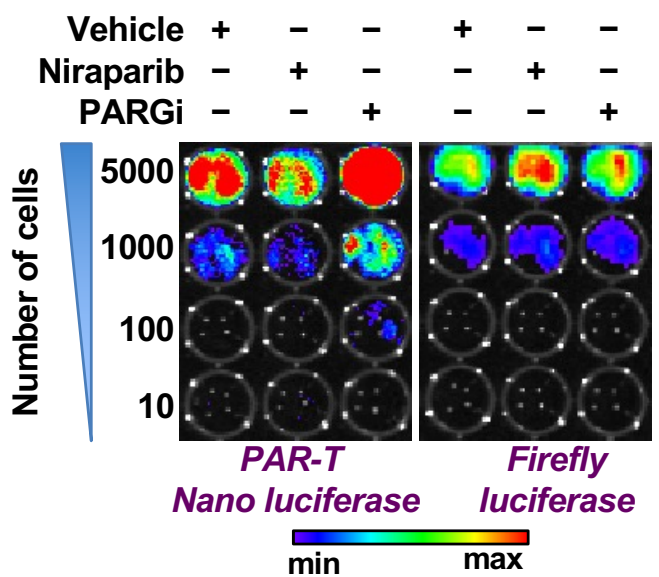

B

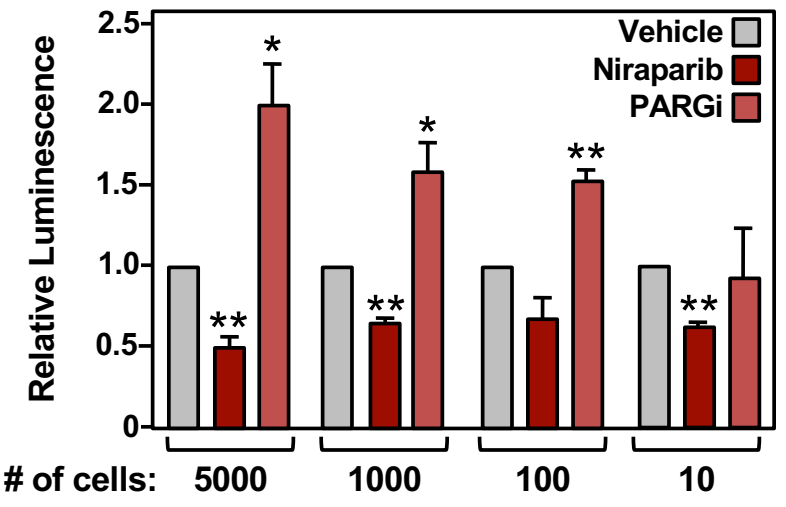

Figure 5 - figure supplement 1. Measuring the levels of PAR in a limited number of cells using PAR-T Nano luciferase.

(A and B) Bioluminescence imaging (A) of the indicated number of 231-PAR-T Luc cells. Each bar in the graph in (B) represents the mean \pm SEM of the relative levels of the ratio of luminescence of Nano luciferase to firefly luciferase $(\mathrm{n}=3$, t-test $* \mathrm{p}<0.05$ and $* * \mathrm{p}<0.001)$. 